\title{
Moving to Inequality: Neighborhood Effects and Experiments Meet Social Structure
}

\section{Citation}

Sampson, Robert J. 2008. “Moving to Inequality: Neighborhood Effects and Experiments Meet Social Structure." American Journal of Sociology 114 (1) (July): 189-231. doi:10.1086/589843.

\section{Published Version}

doi: $10.1086 / 589843$

\section{Permanent link}

http://nrs.harvard.edu/urn-3:HUL.InstRepos:17819440

\section{Terms of Use}

This article was downloaded from Harvard University's DASH repository, and is made available under the terms and conditions applicable to Other Posted Material, as set forth at http:// nrs.harvard.edu/urn-3:HUL.InstRepos:dash.current.terms-of-use\#LAA

\section{Share Your Story}

The Harvard community has made this article openly available.

Please share how this access benefits you. Submit a story.

\section{Accessibility}




\title{
Moving to Inequality: Neighborhood Effects and Experiments Meet Social Structure ${ }^{1}$
}

\author{
Robert J. Sampson \\ Harvard University
}

\begin{abstract}
The Moving to Opportunity (MTO) housing experiment has proven to be an important intervention not just in the lives of the poor, but in social science theories of neighborhood effects. Competing causal claims have been the subject of considerable disagreement, culminating in the debate between Clampet-Lundquist and Massey and Ludwig et al. in this issue. This article assesses the debate by clarifying analytically distinct questions posed by neighborhood-level theories, reconceptualizing selection bias as a fundamental social process worthy of study in its own right rather than a statistical nuisance, and reconsidering the scientific method of experimentation, and hence causality, in the social world of the city. The author also analyzes MTO and independent survey data from Chicago to examine trajectories of residential attainment. Although MTO provides crucial leverage for estimating neighborhood effects on individuals, as proponents rightly claim, this study demonstrates the implications imposed by a stratified urban structure and how MTO simultaneously provides a new window on the social reproduction of concentrated inequality.
\end{abstract}

Contemporary wisdom traces the idea of neighborhood effects to William Julius Wilson's justly lauded book, The Truly Disadvantaged (1987). Since its publication, a veritable explosion of work has emerged, much of it attempting to test the hypothesis that living in a neighborhood of con-

\footnotetext{
${ }^{1}$ I am indebted to Corina Graif for superb research assistance and to Patrick Sharkey for his collaborative work on neighborhood selection. They both provided incisive comments as well, as did Nicholas Christakis, Steve Raudenbush, Bruce Western, P.-O. Wikström, Bill Wilson, and Chris Winship. I am grateful for the collective feedback on my ideas. I also wish to express my sincere thanks to Jens Ludwig and Lisa Sanbonmatsu for their assistance in making portions of the Moving to Opportunity data available for the analyses presented in this article. Direct correspondence to Robert J. Sampson, Department of Sociology, Harvard University, William James Hall, 33 Kirkland Street, Cambridge, Massachusetts 02138. Email: rsampson@wjh.harvard.edu
}

(C) 2008 by The University of Chicago. All rights reserved.

0002-9602/2008/11401-0006 $\$ 10.00$

AJS Volume 114 Number 1 (July 2008): 189-231 


\section{American Journal of Sociology}

centrated poverty has pernicious effects on a wide range of individual outcomes-economic self-sufficiency, violence, drug use, low birth-weight, and cognitive ability, to name but a few. ${ }^{2}$

There is, however, an earlier neighborhood effects tradition that charted a different course (Wilson 1987, pp. 165-66; Sampson and Morenoff 1997). Although not opposing the prediction of individual outcomes, urban sociologists of the classical Chicago school were instead fixated on the structural consequences of urbanization for the differential social organization of the city, especially its neighborhoods. Prominent questions included how the culture and structure of a community-for instance, its capacity for social control or the age-graded transmission of social norms-were influenced by economic segregation and ethnic heterogeneity, and how this process shaped delinquency rates (Park and Burgess 1925; Shaw and McKay 1942). The unit of analysis was thus not the individual but rates of social behavior that varied by neighborhood-level cultural and social structure. ${ }^{3}$ The theoretically implied unit of intervention was the community itself. To this day, though little-heralded, interventions such as the Chicago Area Project survive. ${ }^{4}$

Broadly stated, then, two distinct approaches to neighborhood effects have been put forth, and in different intellectual eras one or the other has dominated. Each approach is important to the advancement of scientific knowledge and the design of social policy. Yet there can be little doubt which one dominates current social inquiry, especially in the policy world. The question of the day has turned ever more sharply in one direction-in essence, the phrase "neighborhood effects" has come to stand

\footnotetext{
${ }^{2}$ On the heels of Wilson (1987), Jencks and Mayer (1990) provided an extensive evaluation of existing research on the effects of growing up in neighborhood poverty. More recent and general syntheses of neighborhood effects may be found in Leventhal and Brooks-Gunn (2000) and Sampson, Morenoff, and Gannon-Rowley (2002). The latter article shows how the volume of neighborhood effects publications increased sharply in the 1990s, soon after the publication of Wilson (1987). Yet Sampson et al. (2002, p. 444) also show sharp publication increases in the pre-Wilson 1960s and mid-1970s.

${ }^{3}$ The Chicago school can in turn be situated in earlier traditions, spawned by social statisticians and epidemiologists in Europe ranging back at least to Quetelet, but perhaps best illustrated in the great works dissecting the social structure of Victorian London (Mayhew 1862; Booth 1889). Wilson's work, in my view, is rooted in these earlier traditions. Rereading The Truly Disadvantaged, one is struck by its structuralist bent, though this was rather quickly translated by policy-oriented researchers into a prediction about individual outcomes.

${ }^{4}$ Schlossman and Sedlak (1983) provide a detailed, though now-dated, review of the idea and empirical content of the community-level interventions animating the Chicago Area Project. The project is soon to celebrate the 75th anniversary of its founding. Population-level interventions are better established in public health, including the experimental randomization of macrolevel ecological units to causal treatments (Boruch and Foley 2000; Sikkema et al. 2000).
} 
MTO Symposium: Moving to Inequality

for effects on individual outcomes. Moreover, the specter of "selection bias" has been raised to cast doubt on almost all observational research, a nuisance to be extinguished with what is widely claimed as the most scientific of all methods, the experiment.

Enter the Moving to Opportunity (MTO) experiment. Bursting onto the scene with a splash and following the path of contemporary wisdom, MTO has been framed as a test of Wilson's hypothesis in The Truly Disadvantaged (Ludwig et al. 2008 [in this issue]). MTO publications and presentations appear to have cast doubt on the general thesis that neighborhoods matter in the lives of poor individuals. At least, that is the message that many, including myself, have heard up to now. ${ }^{5}$ With the weight of the experimental method behind them, scholars have made broad assertions about the best way to conduct research, the validity of theories of neighborhood effects writ large, and the direction that policy should take. For example, because MTO "used randomization to solve the selection problem," it has been said to offer "the clearest answer so far to the threshold question of whether important neighborhood effects exist" (Kling, Liebman, and Katz 2007, p. 109; see also Oakes 2004). Given that over a century of neighborhood ecological research forms the baseline, this is high praise for one study. Or consider this headline: "Improved Neighborhoods Don't Raise Academic Achievement," from the National Bureau of Economic Research (NBER 2006). That may well be true, but one wonders how such a strong inference could be drawn from a study that randomly assigned housing vouchers to individual families rather than improving neighborhoods. Put differently, MTO is not a neighborhood-level intervention. To top things off, Clampet-Lundquist and Massey (2008 [in this issue]) charge that small differences in neighborhood racial integration induced by MTO's random allocation of housing vouchers do not offer a robust test of neighborhood effects.

It is no wonder that scholars have been puzzled and that controversy has grown. Despite MTO's strengths in the experimental end of social inquiry, disagreement reigns over the question of how to analyze and generalize from a housing-voucher study, designed to assess individual outcomes among the extreme poor, to all of neighborhood-level theory. What constitutes the proper interpretation and statistical analysis of MTO, and what effect is being estimated? To what populations and levels of analysis can we infer neighborhood treatment effects? What does the treatment capture, and was it sufficient? What theory does MTO test?

${ }^{5}$ The media has interpreted MTO in the "negative" as well. A major Washington Post article from 2007 is typical: "Neighborhoods' Effect on Grades Challenged: Moving Students out of Poor Inner Cities Yields Little, Studies of HUD Vouchers Say" (August 14, p. A2). 


\section{American Journal of Sociology}

Perhaps more fundamentally, what is a neighborhood effect? There could hardly be a better time for the American Journal of Sociology to provide the intellectual context for thinking seriously about these questions, for not only are the questions foundational, but the answers are likely to reverberate widely in the social sciences. The motivation for renewed reflection stems from an article that questions and then reanalyzes the causal treatment in MTO (Clampet-Lundquist and Massey), paired with a response that defends MTO and its mandate (Ludwig et al.). The good news is that these dual scholarly interventions move the field forward by providing new analyses, new insights, needed clarifications, and most important, an opportunity to reconsider the very idea of neighborhood effects. The articles in question are also exceptionally clear and collegial, models of scholarship as it should be.

Although I applaud the authors and find much to agree with in both articles, a dispute nonetheless remains. The crucial disagreements in the debate turn on the proper analytic approach to neighborhood selection in an experimental design and the strength of the MTO treatment itself. It is on these two issues that I focus most of my attention. To enrich the debate, I present a targeted set of new analyses of MTO data, along with original data from a longitudinal observational study that complements in time and space one of the MTO sites, allowing direct comparison of patterns of residential movement. My thesis grants validity to each article, accepting key conclusions of Ludwig et al. while highlighting, in a way that supports Clampet-Lundquist and Massey (hereafter, "CM"), the nature of causality in a socially segregated and stratified world. I also argue for alternative ways to conceive of neighborhood effects, selection bias, causal knowledge, and, at bottom, the social structure of inequality. Ironically, the individualistic intervention of MTO turns out to provide an intriguing alternative vehicle for observing the reproduction of inequality. ${ }^{6}$

\section{MTO BASICS}

I paint the picture of baseline facts with a broad brush because lucid accounts have filled in the details elsewhere, including not just the two

\footnotetext{
${ }^{6}$ There are many issues of concern in neighborhood effects research that, for the most part, I set aside because of space limitations, such as the operational unit of measurement (e.g., block, census tract), statistical tools for assessing ecological properties ("ecometrics"), and theories and measures of mediating social mechanisms. Their omission implies not a lack of importance but a desire to concentrate on the major issues raised by the debate at hand. For further discussion of measurement and statistical issues not covered here, see the recent contributions of Hipp (2007) and Raudenbush and Sampson (1999). For further discussion and review of the "social process" turn in neighborhood effects research, see Sampson et al. (2002). What we mean empirically by "neighborhood" cannot be ignored, however; I revisit this issue later.
} 
MTO Symposium: Moving to Inequality

articles in question but also prior reviews (notably, Goering and Feins 2003; Orr et al. 2003; Kling et al. 2007). The design of MTO is relatively straightforward. Families below the poverty line and living in concentrated poverty ( $40 \%$ or greater) in five cities in the mid-1990s were deemed eligible to apply for housing vouchers. Those that did so were randomly assigned to one of three groups: experimental, Section 8, or control. The experimental group was offered a housing voucher that, if used, had to be applied toward residence in a neighborhood with less than $10 \%$ poverty. Counseling and assistance in housing relocation were also provided. Those in the Section 8 group were offered vouchers with no restrictions imposed on where they could move. The controls were given no treatment. The baseline population eligible for the voucher study was not only poor but predominantly black or Latino, and it comprised mainly female-headed families on welfare living in concentrated public housing-or what many would term the "ghetto"-circa 1995-97.

To use a slightly oversimplified typology, the five main outcomes that have been studied are adult economic self-sufficiency, mental health, physical health, education, and risky behavior. No significant differences between experimentals and controls have been reported by MTO researchers for adult economic self-sufficiency or physical health, though CM challenge the findings on the former. Significant positive effects of the MTO intervention have been reported for adult mental health, young female education, physical and mental health of female adolescents, and risky behavior (e.g., crime, delinquency) among young girls. Long-term adverse effects of moving are found for the physical health and delinquency of adolescent males in the MTO sample. ${ }^{7}$ And null effects have been reported for a number of outcomes, such as cognitive achievement. Complexities in the interpretation of MTO thus extend beyond the critique by CM.

It seems reasonable to conclude from all this that the MTO results are mixed rather than negative-conditional on outcome and subgroup. That is to say, sometimes neighborhood effects matter, sometimes they do not. This state of affairs hardly seems surprising. After all, it would be astonishing, suspicious even, if neighborhood effects were found across the board for all outcomes, all measures. Nothing in social science is that robust, and no theory of which I am aware posits ubiquitous or large neighborhood effects on everything. Besides, it is a mistake to equate small effect sizes with unimportance, especially if the effects are obtained under unusual circumstances, as seems to the case here (Prentice and

\footnotetext{
${ }^{7}$ Girls thus appear to do better under experimental conditions, boys worse. First-round findings reporting crime-reduction effects for boys (Ludwig, Hirschfield, and Duncan 2001) raise a puzzling gender-linked developmental question that is beyond the scope of this article.
} 
American Journal of Sociology

Miller 1992). Moreover, some of the effects reported, such as those on adult mental health and female adolescent behavior, are rather large in magnitude. Because depression is implicated in many life-course sequelae (Langer and Michael 1963), experimentally induced neighborhood effects in the mental health domain are especially notable. ${ }^{8}$

So why the disproportionate emphasis, especially in public pronouncements, on the idea that MTO has disproven neighborhood effects? This is an important question, and I suspect one answer is simply that debunking is both tempting and important. Problems set in when debunking is combined or set up with a disciplinary straw man. Over time, however, the complexities have become more apparent, and by now, all sides have moderated and seem to be declaring a truce of sorts. Ludwig et al. themselves argue that it is unfortunate that MTO has been interpreted in "overly negative" terms (p. 157), and I find their summary of MTO evidence exceedingly fair.

The time therefore appears ripe for an interdisciplinary assessment of what we might term the "neighborhood question, experimental style." I take a broad evaluative stance, one compelled by the reach of Ludwig et al.'s article and reflected in its title: "What Can We Learn about Neighborhood Effects from the Moving to Opportunity Experiment?"

\section{LEVELS AND SCOPE OF INFERENCE}

In the counterfactual paradigm advocated by Ludwig et al., the general question is whether the same individual, residing in a poor neighborhood, would follow a different course if he or she in fact resided in a nonpoor neighborhood. Individuals are the unit of analysis and selection bias is the main concern. Randomly assigning individuals to neighborhood treatment is the scientifically proposed way to equate otherwise dissimilar people, permitting estimation of an average causal effect. Of course, MTO did not (and could not) assign persons to specific neighborhoods or homes. Housing vouchers were randomly assigned, and individuals were induced to move.

A separate question is how to explain variations in rates of behavior or events across neighborhoods. Here, the counterfactual is about not individuals but neighborhoods, leading to experiments (even if only thought experiments) in which neighborhoods are randomly allocated to treatment and control conditions and a macrolevel intervention is introduced. Ludwig et al. (p. 182) properly caution readers not to draw infer-

\footnotetext{
${ }^{8}$ Ludwig et al.'s comment signals a welcome change in direction: MTO work is now taking social-psychological and even biological mechanisms increasingly seriously.
} 
MTO Symposium: Moving to Inequality

ences from MTO about neighborhood interventions, but this is something social scientists have seemed eager to do. I would go further and argue that the community-level causal question is not only interesting and compelling, but equal in intellectual integrity to the individual-level question. By this logic, it follows that research needs to take seriously the measurement and study of neighborhoods as important units of analysis in their own right, especially with regard to social and institutional processes (Raudenbush and Sampson 1999).

It is important to emphasize that a theory aiming to explain concurrent neighborhood-level variability is logically not the same thing as one that explains how neighborhoods exert long-term effects on individual development (Wikström and Sampson 2003). For example, we may have a theory of social control that accurately explains variation in crime event rates across neighborhoods regardless of who commits the acts (residents or others), and another that accurately explains how neighborhoods influence the individual behavior of their residents no matter where they are. In the latter case, neighborhoods have developmental or enduring effects, and in the former, situational effects. ${ }^{9}$ The two types of effects are not mutually exclusive. The logical separation of explanation is reinforced by considering routine activity patterns in contemporary cities, where residents typically traverse the boundaries of multiple neighborhoods during the course of a day.

In short, if we want to learn about the causal effects of neighborhood interventions in an experimental design, the proper method is to randomly assign interventions at the level of neighborhoods or other ecological units, not at the individual level. Examples include the random assignment of neighborhoods to receive a network-based AIDS intervention, community policing, or an effort to mobilize collective efficacy (e.g., Sikkema et al. 2000). If rates of sexually transmitted diseases or public violence were significantly reduced after the randomized interventions, or if dissimilar outcomes in particular (e.g., civic trust, social interactions) were affected, we might then speak of an emergent neighborhood-level effect. From a public policy perspective, neighborhood- or population-level interventions may be more cost-effective than those targeted to individuals. ${ }^{10}$

\footnotetext{
${ }^{9}$ Recent research in Chicago, e.g., shows that while collective efficacy (social control combined with cohesion) predicts the event rate of violence in a neighborhood, it does not predict rates of offending by neighborhood adolescents, which may occur anywhere. ${ }^{10}$ The HOPE VI federal housing program and the New Communities Program of the MacArthur Foundation represent examples of a governmental and a private intervention at the macrolevel. I make no claims here regarding the success or failure of these programs; the point is to bring further contrast to the individual vs. neighborhood question. For a counterfactual approach to neighborhood interventions, see Verbitsky and Raudenbush (2006).
} 
American Journal of Sociology

Neighborhood Effects for Whom? On What?

The MTO program was restricted to a narrow slice of the population. Those eligible to participate in MTO were poor families with children living in public housing, in neighborhoods with poverty rates over $40 \%$. In cities like Chicago, this meant that participants were virtually all black (98\%) and nonmarried (93\%) and from female-headed (96\%), extremely poor households, with mean total income less than $\$ 8,000$ (Orr et al. 2003, app. C2). To get an idea of just how small a slice this restriction produces, I calculated the falloff from a representative sample after applying an MTO "adjustment" to the Project on Human Development in Chicago Neighborhoods (PHDCN). Described in more detail below, PHDCN selected over 4,500 families with children under the age of 18 at almost exactly the same time as MTO was selecting families in Chicago, in 1995. The sample was designed to be representative of the population of children growing up in Chicago at the time. There was not a good measure of living in public housing at baseline, so I selected those families headed by a black, nonmarried female, receiving welfare and living in a neighborhood with greater than $40 \%$ poverty. Judging from published MTO data, this selection characterizes the MTO Chicago site-if anything, it is probably a generous definition, as it includes some families not in public housing. Out of approximately 4,600 families, 139 fit the MTO criteria. Thus, with weighting to account for the stratified sampling scheme, $5 \%$ of the PHDCN population is MTO equivalent. These MTO "equivalents" establish how far into the extreme tail of the poverty and race distributions the MTO study reaches: $5 \%$ of the population does not a general test of neighborhood effects make.

It is likewise important to appreciate the implications of the fact that at baseline, MTO adults and their children had for the most part grown up in high-poverty neighborhoods, which raises a developmental question about life-course timing and the durability of neighborhood effects. If the effect of disadvantage is cumulative, lagged, or most salient early in life, as recent evidence suggests with respect to cognitive ability and adolescent mental health (Wheaton and Clarke 2003; Sampson, Sharkey, and Raudenbush 2008), then moving, while still potentially important, does not bear on perhaps the most critical neighborhood influences in early childhood. In this sense, the MTO experiment may be inconsistent with theoretical perspectives that emphasize early brain development and critical periods when contextual effects get "locked in" (Shonkoff and Phillips 2000, chap. 8). This problem becomes even more complex if we consider that most families living in severely disadvantaged neighborhoods have lived in similar environments for multiple generations (Sharkey 2008), 
MTO Symposium: Moving to Inequality

raising the possibility that the influence of disadvantage extends across generations.

The "outcome" question is another issue. Should we expect neighborhood effects on all manner of phenomena? A vast number of individual outcomes have been subjected to the MTO design. In one recent study, there is a web appendix with over 100 pages of outcomes (Sanbonmatsu et al. 2006). Although the detail is impressive, it is also theoretically confusing. The classical social organizational theories of the Chicago school, and many contemporary revisions, hypothesized specific pathways by which social mechanisms were differentially related to various phenomena, such as delinquency rates (Shaw and McKay 1942) and mental disorders (Faris and Dunham 1939). Social disorganization theory, for example, specifies a hypothesized link running from concentrated disadvantage, instability, and heterogeneity through diminished adult control of peer groups, gang formation, and eventually delinquency (Sampson and Morenoff 1997, pp. 16-20). It is notable in this light that some of the strongest findings to date on MTO pertain to crime and mental health. But when neighborhood effects theory is invoked, Ludwig et al. (p. 147) cite Wilson (1987) as proposing one of the "original theories" to claim that neighborhood effects primarily touch poor individuals and economic outcomes- the spatial mismatch hypothesis in particular. Neighborhood effects (and Wilson) are simultaneously broader and more specific than that, and I would not consider spatial job mismatch to be one of the more compelling neighborhood theories.

What Are the Social Mechanisms and the Ultimate Causal Question?

As Ludwig et al. note (p. 151), MTO "bundles" the neighborhood treatment and does not tell us about why neighborhoods matter for individuals, if they do. When MTO families move from one neighborhood to another, entire bundles of variables change at once, making it difficult to disentangle change in neighborhood poverty from simultaneous changes in other structural factors and social processes (Katz, Kling, and Liebman 2001, p. 621). Even with a nonbundled treatment, the social mechanisms underlying neighborhood effects in MTO are rendered invisible. This is not a flaw in MTO; rather, it speaks to the role of experiments in scientific research-experiments do not reveal causal explanation in any direct sense. Nor does any technique, be it matching or instrumental variables. Causal explanation requires theory and concepts that organize knowledge about (typically) unobserved processes or mechanisms that bring about the effect (Heckman 2005; Morgan and Winship 2007, chap. 8).

Further, although moving is a major life event associated with negative outcomes for youth (Hagan, MacMillan, and Wheaton 1996; Haynie and 
American Journal of Sociology

South 2005), neighborhood change is coupled with moving by the MTO design. Hence, MTO cannot (experimentally) separate the impact of moving itself from differences in neighborhood context. Similarly, MTO cannot estimate the impact of moving into poverty, or the effect of neighborhood change on stayers.

We can now better appreciate the causal question MTO asks. The study is spot-on for answering the policy question, Does the offer of a housing voucher to move to a nonpoor neighborhood affect the later outcomes of the extremely poor? One might add, Does it do so for those who have grown up in poverty and arguably have already experienced its developmental effects? The MTO question is certainly of substantial interest to policy makers who are considering whether to provide vouchers to induce mobility among the very poor. But should housing policy for a select group of the population be in the driver's seat when numerous other questions derived from neighborhood effects theory are at stake? To my mind, the claim that MTO is scientifically superior because it experimentally addresses the "threshold" question of whether neighborhoods matter in the first place is only correct to the extent that $(a)$ we consider the voucher-induced mobility question answered by MTO to be broadly and accurately reflective of neighborhood contextual effects, $(b)$ we stick to individual-level inference and set aside neighborhood-level interventions, and $(c)$ we bracket causal theory of the mechanisms that produce neighborhood effects and selection into the treatment—or what Holland (1986) termed the "causes of the effect."

\section{Selection Bias and MTO}

Any discussion of selection into treatment leads inevitably to something that represents the undeniable strength of MTO and yet one of the major disagreements in this debate. Set within the inherent limits imposed by the MTO design as summarized so far, the experimental allocation of treatment is very important. I believe that MTO is a major advance to social science and I agree with almost everything Ludwig et al. claim in terms of its ability to solve the selection bias "curse" (p. 150). ${ }^{11}$ Although neighborhood selection bias is an old issue, Jencks and Mayer (1990; Mayer and Jencks 1989) can be considered the foremost source of late20th-century anxiety over it. In a widely cited critique, they essentially asked the question, How do we know that the neighborhood differences

\footnotetext{
${ }^{11}$ I would further argue that most of the misunderstandings of MTO stem not from the investigators or authors but from the "consumers" of the MTO product; this points again to the value of this symposium in airing a broad set of issues. The lure of an experiment is apparently hard to resist.
} 
MTO Symposium: Moving to Inequality

in any outcome of interest are the result of neighborhood factors rather than the differential selection of adolescents or their families into certain neighborhoods? They concluded that we do not know.

For this reason, it is important to underscore the validity of Ludwig et al.'s claim (p. 151) that selection bias in observational research raises a hornet's nest of analytic problems that MTO does solve at the individual level of inference and in terms of balancing the data on unobservables (even allowing that a substantial proportion of participants did not take up the offer of a voucher). The randomized design of MTO sets it apart from volumes of research published in our journals that rely on ex post explanations, typically derived from regression models that load up on individual-level control variables and leave undefined the causal counterfactuals under study. In promoting MTO, Ludwig et al. worry mainly about omitted variable bias in studies of this sort-their concern is that there is some (undefined, unobserved) quantity out there that we have failed to measure after all these years, or cannot measure. Hence the experiment.

Yet I worry as much if not more about what I will call the included variable bias problem, one that, while more subtle, wreaks just as much havoc on observational research. Consider that many (most?) of the covariates that make their way into typical regression models represent potential causal pathways by which the neighborhood may influence the outcome of interest. For example, in an attempt to account for characteristics of individuals and families that might influence both selection into poor neighborhoods and individual outcomes, observational studies often include control variables such as income, family structure, depression, health problems, criminality, physical disabilities, education, and peer influence. But if we are to interpret resulting estimates as a test of neighborhood effects, we must make the assumption that all controls are pretreatment covariates - that is, they are unaffected by neighborhood. This is an unwarranted assumption, given the existence of a long line of research positing neighborhood effects on health, family norms, family structure, adult labor-market outcomes, and more (Duncan and Raudenbush 2001; Sampson et al. 2002).

The larger point is that the common practice of estimating "direct" neighborhood effects using regression-based approaches that control for endogenous covariates has the net result of distorting the multiple pathways by which neighborhoods may influence developmental outcomes, especially among children, and thereby inducing bias. ${ }^{12}$ The introduction of time-varying covariates makes things even worse, and propensity

${ }^{12}$ Although for somewhat different reasons, the indiscriminate use of control variables was the subject of a detailed warning by Lieberson over 20 years ago (1985, chap. 6). 
American Journal of Sociology

matching alone is not a sufficient solution for addressing developmental processes. If observational data are to be used in a dynamic framework, then new approaches are required. Fortunately, there are promising methods that can integrate a dynamic life-course framework with neighborhood effects. Before turning to this line of inquiry, however, it is necessary first to assess CM's claim about the treatment itself: understanding the nature of the treatment in MTO is directly linked to formulating effective analytic strategies.

\section{SEGREGATION AND NEIGHBORHOOD TREATMENTS}

The realized change in neighborhood environments among families receiving vouchers is questioned by CM because the experimental group moved from and to largely segregated black areas, which were subject to the reinforcing disadvantages highlighted in the work of Wilson (1987) and Massey and Denton (1993). The initial experimental/control group differences-even in poverty-diminished over time as families increasingly moved back into neighborhoods similar to those at baseline. Further, children in the MTO experimental group attended schools that differed little from those of children in the control group in terms of racial composition, average test scores, and teacher/pupil ratio. In fact, impacts on school environments were "considerably smaller than impacts on neighborhoods" (Sanbonmatsu et al. 2006, p. 649). CM are thus not surprised that moving within segregated neighborhood contexts, even with improvements in economic status, would produce small effects on adult economic self-sufficiency. In response, Ludwig et al. claim that large differences in neighborhood poverty were produced - the goal of MTO.

As I read CM, their argument is about not just racial composition but its entanglement with resource deprivation and disadvantage. They are not equating racial composition with poverty or disadvantage in an essentialist way, in other words; rather, the argument is that social allocation processes in the United States, with its particular history of race relations, have led to acute sorting along racial-economic cleavages that disadvantage blacks (pp. 115-16). One can imagine, and one can find, other societies in which segregation processes that link ascriptive with achieved characteristics are not present or at least not as severe. In order to assess the implications of the race-disadvantage nexus relative to poverty alone, I examine two distinct issues and kinds of data. I first analyze the structure of MTO participants' residential moves across multiple social dimensions and levels of neighborhood, both static and dynamic. Second, I consider the implications of social-ecological confounding for selection bias more generally by analyzing patterns beyond the MTO sample. 
MTO Symposium: Moving to Inequality

MTO Trajectories

I analyze data from the Chicago MTO site because it permits a strategic comparison with the PHDCN study introduced above, a study that entails a detailed set of neighborhood-level measures of the city and metropolitan area. This choice simultaneously yields other strategic benefits. Chicago is representative or in the middle of the MTO strength-of-treatment distribution (Ludwig et al., fig. 1), ensuring that there is no "stacking of the deck" in favor of either side in the debate. Further, Chicago was the site of much of Wilson's (1987) work, a key motivator for MTO.

My goal is to examine neighborhood attainment as the outcome of the treatment, not individual characteristics such as crime or economic selfsufficiency. Following MTO publications, I begin with census tracts as operational units, which is made possible by linking geocoded address data over time. If the MTO intervention made a fundamental or lasting difference in residential location, this will be reflected in where people are living several years out and not just a short time after the experiment, when voucher moves were restricted. To test this, I examine neighborhoods of residence at the follow-up in 2002, about six to seven years after the experiment began. It is important to note that the average number of years lived at the destination address was 3.38 for experimentals and 3.29 for controls (not significantly different), a substantial rather than fleeting amount of time.

I focus mainly on a holistic measure of concentrated disadvantage, drawing on a long line of research demonstrating the clustering of racial and socioeconomic segregation across time and multiple levels of ecological analysis (e.g., Land, McCall, and Cohen 1990; Massey and Denton 1993; Sampson and Morenoff 1997). Building on this prior work and existing theory, Sampson et al. (2008) recently examined six characteristics of census tracts, taken from the 1990 and 2000 U.S. census: poverty, unemployment, welfare receipt, female-headed households, racial composition (percent black), and density of children. For the city of Chicago and the United States as a whole (representing over 65,000 census tracts), only one linear factor could be reliably extracted in each decade on the basis of a principal components analysis (see Sampson et al. 2008, table 1). Consistent with urban theory, CM, and prior research, the data confirm that race, family structure, and resource deprivation are ecologically knotted at the neighborhood level, not just in Chicago but across the United States (Massey and Denton 1993). I therefore focus on a summary scale of concentrated disadvantage rather than a single item. ${ }^{13}$

${ }^{13}$ The only real difference in pattern between the United States and Chicago is that children are more exposed to concentrated poverty in Chicago. Although it makes no substantive difference, for this reason I set aside density of children and examine a 
American Journal of Sociology

Recall that MTO began with high-poverty neighborhoods, which in Chicago were clustered in a small number of census tracts on the south side of Chicago in the Grand Boulevard, Douglas, and Oakland communities. Figure 1 shows the tight clustering. Where did the experimental families move? Figure 2 gets to the heart of the debate by depicting the location of participants at the end of the last follow-up evaluation, mapped across the Chicagoland area. (There is no treatment difference in staying$92 \%$ of both groups remained in the metropolitan area). The two panels plot destination addresses shaded by the summary index of concentrated disadvantage, trichotomized here for parsimony into equal thirds based on the metropolitan distribution. Following Ludwig et al., I focus primarily on comparisons between the control and experimental groups rather than the selection decisions among compliers alone. Any differences between groups can thus be attributed purely to the experiment.

Figure 2 tells a clear story. MTO movers spread outward from the inner city, but final destinations are highly structured. Entire swaths of Chicago are simply untouched by experimental and control movers alike, as is most of the metro area. Even if we limit the comparison to controls versus self-selected compliers within the treatment group, the same conclusion holds: the vast majority of all MTO participants moved to areas close by other South Side Chicago communities that are in the upper range of concentrated disadvantage. Relatively few moved elsewhere, but when they did the destinations were a systematic cluster of communities on the northwest side as well as close-in suburbs in the southern part of the metropolitan area, again qualitatively similar in concentrated disadvantage. Although there are considerably more experimental group members, and proportionately more of them moved out of the city of Chicago, the observed pattern is striking. The structure of movement appears to be relatively invariant in geographic spread (the $t$-test for distance from origin neighborhoods is not significant) and exposure to entrenched pockets of disadvantage. The modal picture is a dual migration southward along an upside-down $\mathrm{T}$-a spatial regime of concentrated disadvantage.

CM appear justified in their concern: MTO induced residential outcomes over the long run that differ in poverty but not necessarily in racial integration or the constellation of factors that define the concentration of disadvantage. I would further argue that even for poverty the differences are in degree, not in kind. For destination tracts, the experimental reduction in poverty rate was from $42 \%$ to $37 \%$. This reduction of five percentage points (or 15\%, adjusted for compliance) is statistically significant, consistent with Ludwig et al. (weighted $t$-ratio of difference

regression-weighted principal components scale based on the five other indicators. A $z$-score summary scale produces very similar results. 


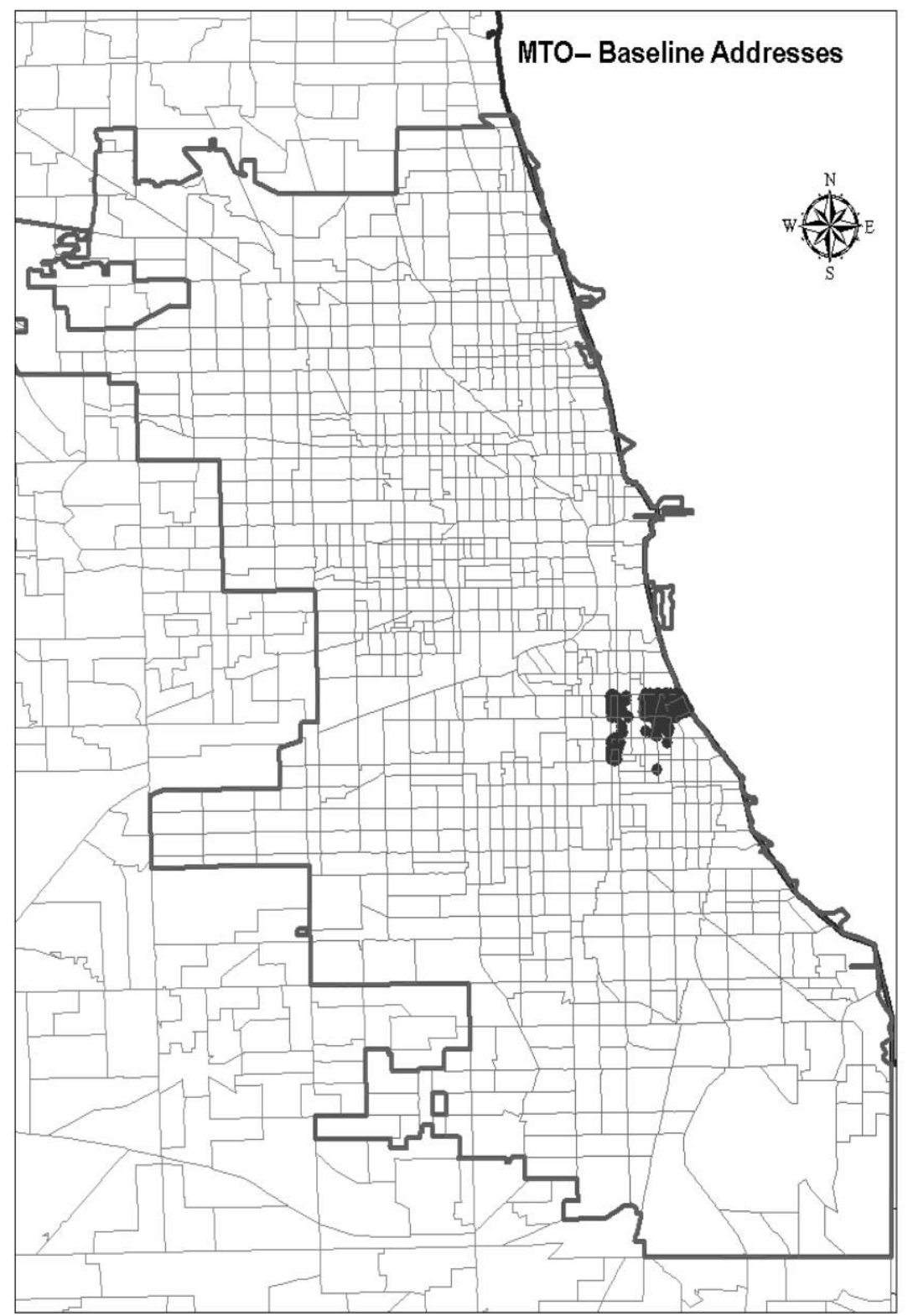

FIG. 1.-Clustering of MTO families at baseline in inner city high-poverty areas of Chicago 


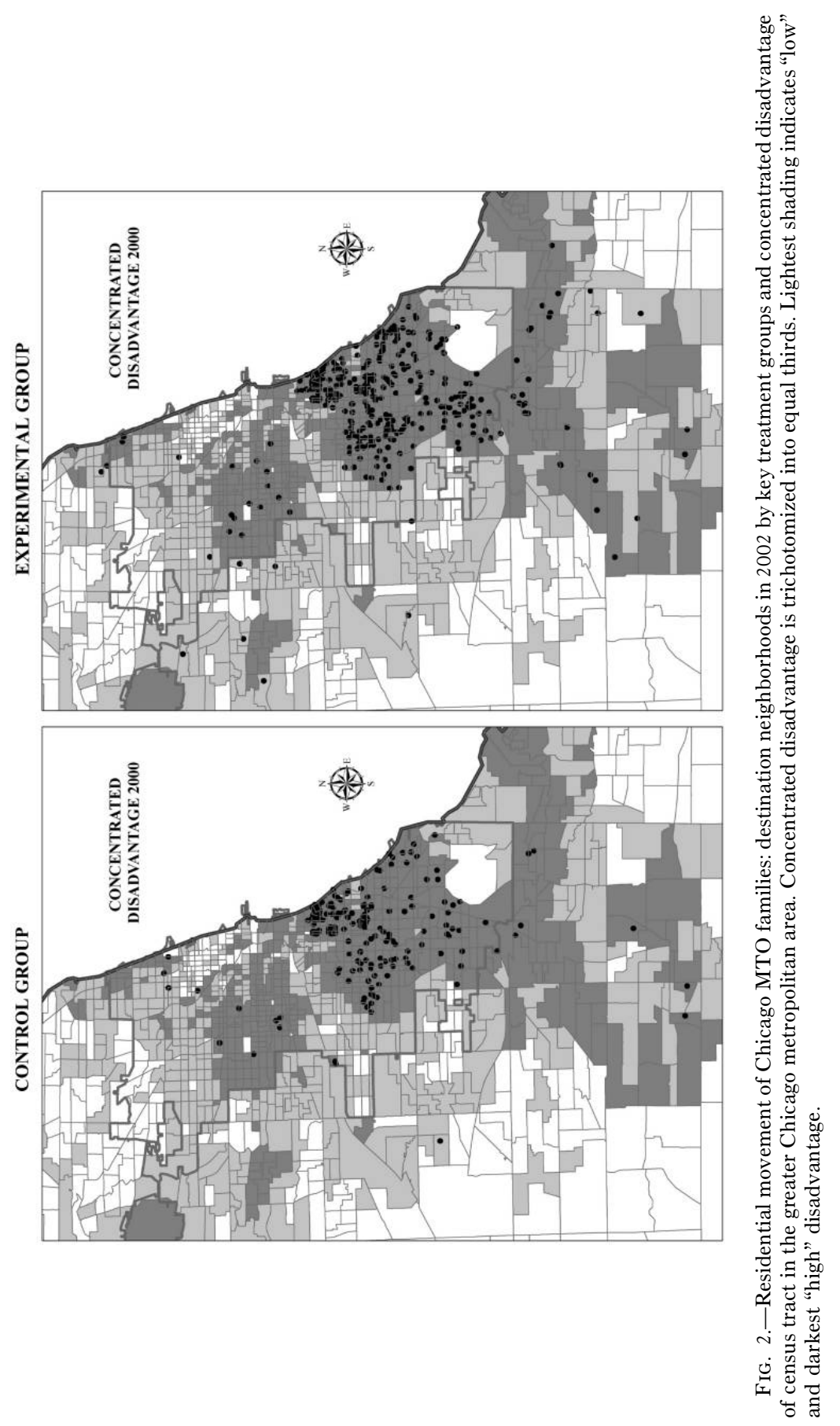


MTO Symposium: Moving to Inequality

$=-2.78)$, but is the glass half-empty or half-full? Consider that experimentals were still living in neighborhoods that by most definitions had high poverty - at levels that the average American will never experience. Aggregated across all five MTO sites, the data also reveal a considerable ( $>30 \%$, on average) poverty rate for both groups (Kling et al. 2007, p. 88 ) and a nontrivial $20 \%$ poverty rate even for compliers. Segregation was barely nudged - both experimentals and controls in Chicago lived at destination in areas that were almost $90 \%$ black (not significant). It is important to note that "scaling up" to account for complier status (see Ludwig et al., p. 153) scales up standard errors too and thus does not change the significance of differences. At other sites, average percent minority is over $80 \%$ for both groups. Linear differences in the principal components scale of concentrated disadvantage, which weights poverty more than race, are significant by treatment group $(P<.05)$. A $z$-score scale including all U.S. and Chicago-area moves is not significantly different. Consistent with figure 2, I thus conclude that while neighborhood poverty differs, as intended, in the end MTO experimental differences are marginal overall and unfolded within similar structural contexts of concentrated disadvantage (see also Clark 2005).

This conclusion is backed up by consideration of additional evidence for neighborhood characteristics that have so far not been central to the MTO discussion. For tracts in Chicago where police data were available, I examined homicide and burglary rates in 2000-2002. Using a community survey of Chicago from PHDCN in 2001-2 that closely matches in time the MTO follow-up, I created neighborhood-level measures (see Raudenbush and Sampson 1999) of social cohesion, intergenerational closure, social control, legal cynicism ("anomie"), reciprocated exchange among neighbors, friendship/kinship ties, tolerance of deviance, organizational participation, victimization, perceived violence, and disorder. Of these more than a dozen characteristics measured independently from MTO, none was significantly different $(P<.05)$ between the experimentals and controls. ${ }^{14}$ Limiting the analysis to Chicago may reduce differences somewhat, given that experimentals were more likely to leave the city than controls (17\% vs. $12 \%)$, but the similarity of neighborhood processes between randomization groups for the vast majority who stayed is evident.

What about interim moves? I have focused on destination neighborhoods for theoretical reasons, but, consistent with MTO publications, I found a significant $(P<.01)$ 9-point difference between the experimental

\footnotetext{
${ }^{14}$ For the measurement properties and theory behind most of these neighborhood-level constructs, see Sampson, Morenoff, and Earls (1999). All $t$-tests use randomization weights recommended in Ludwig et al. As noted above, adjusting for compliance status does not change any conclusions regarding significance.
} 
American Journal of Sociology

and control groups in duration-weighted poverty. However, the durationweighted difference for percent black is only 2 points and is not significant (at the .05 level), supporting CM. To further examine this issue, I follow Kling et al. (2007, p. 87) by presenting in figure 3 density kernel estimates of duration-weighted percent black and poverty. In essence a series of nonparametric smoothed histograms, figure 3 confirms that when we account for average time spent in each tract, MTO's modest poverty effect (top row) was imparted onto a segregated urban structure (bottom row). The density distribution functions for experimentals and controls are virtually indistinguishable in their shape and clustering in the right-hand tail of hypersegregation.

\section{Contextual Dynamics}

Although neighborhoods are quite durable in their relative positioning over time (Sampson and Morenoff 2006), that does not imply an unchanging treatment. To date, the debate about MTO has proceeded largely as though the neighborhoods to which participants moved were sequentially static, like a pill. But neighborhoods have trajectories just like individuals. It follows that we need to consider more than just the level (even if interpolated over time) of neighborhood poverty. I might use a voucher to move to a lower-poverty neighborhood than where a control group member lives, for example, but that neighborhood may be on a downward trajectory (e.g., with declining house values) while the control neighborhood is stably poor. The question is whether there are treatment differences in the rate of change and, ultimately, future viability of neighborhoods. I therefore examine both raw and residual change in percent poverty, percent black, and concentrated disadvantage from 1990 to 2000 and points in between. Residual change offers us the unique advantage of looking at neighborhood change trajectories after removing the effect of larger metropolitan dynamics.

The dynamic picture tells us a different story than the static one. First, there are no significant (at the .05 level) differences between the experimental and control groups in raw changes in percent black or poverty, nor in residual changes in percent black or poverty. Second, there is a modest difference in changes in concentrated disadvantage, but in a direction that favors controls. On average, disadvantage was decreasing over time in Chicago, but the rate of decrease was lower for the experimental group than for the controls. This means that when trajectories of neighborhood change are the outcome criterion, the MTO experiment did not result in the experimental group ending up in better-off neighborhoods. To better show this, figure 4 displays density measures for changes in poverty (upper graphs) and concentrated disadvantage (lower graphs) in 


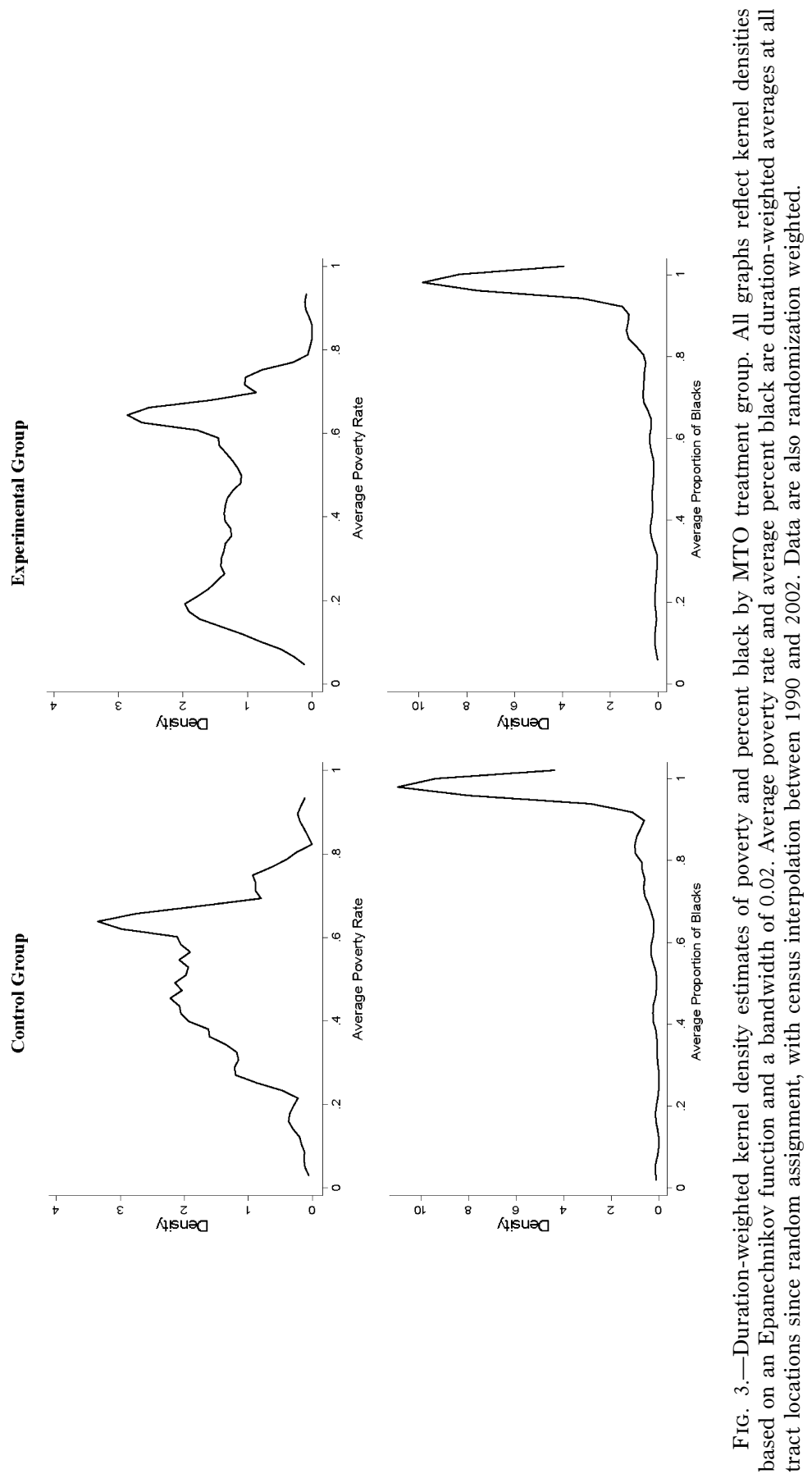




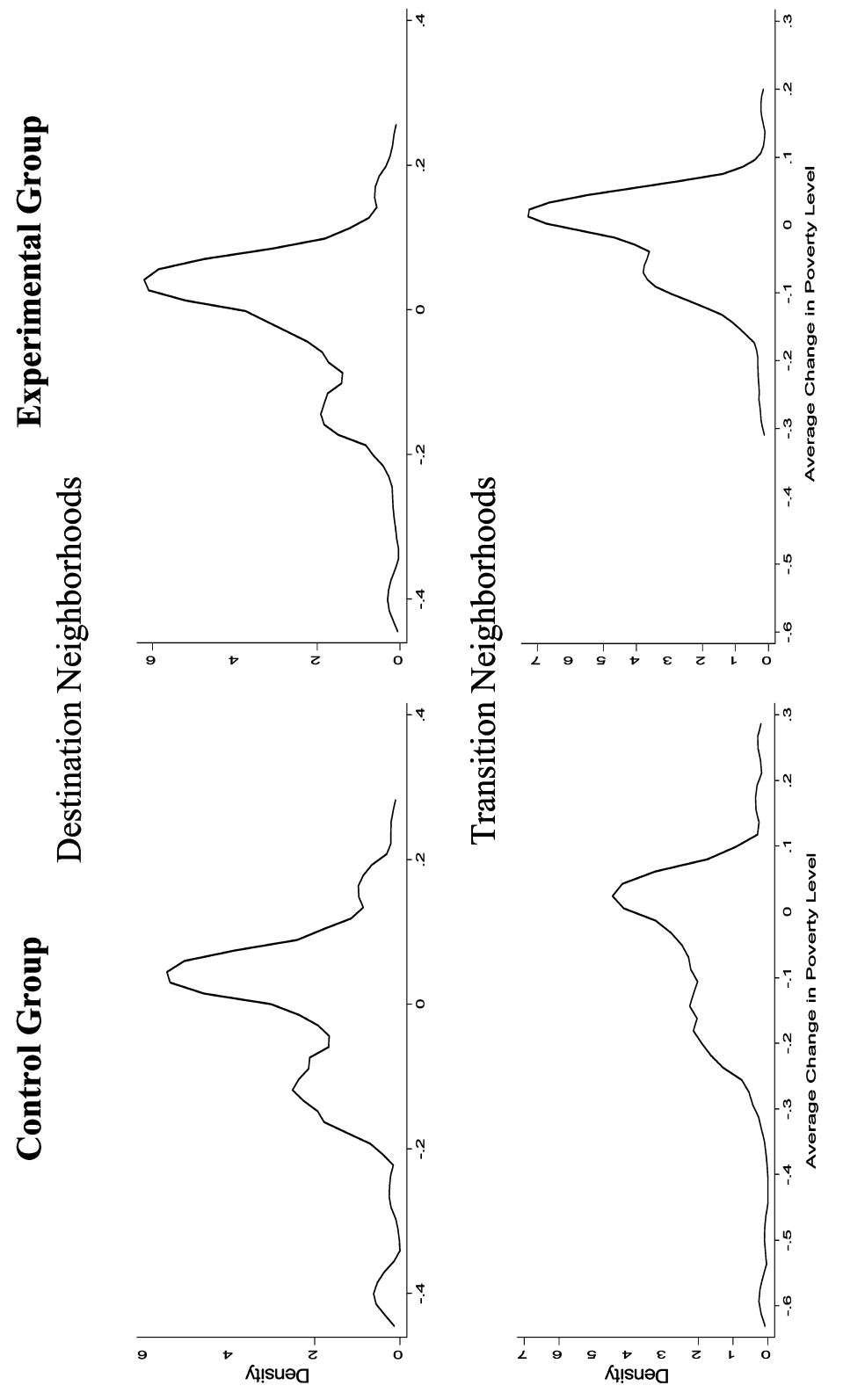




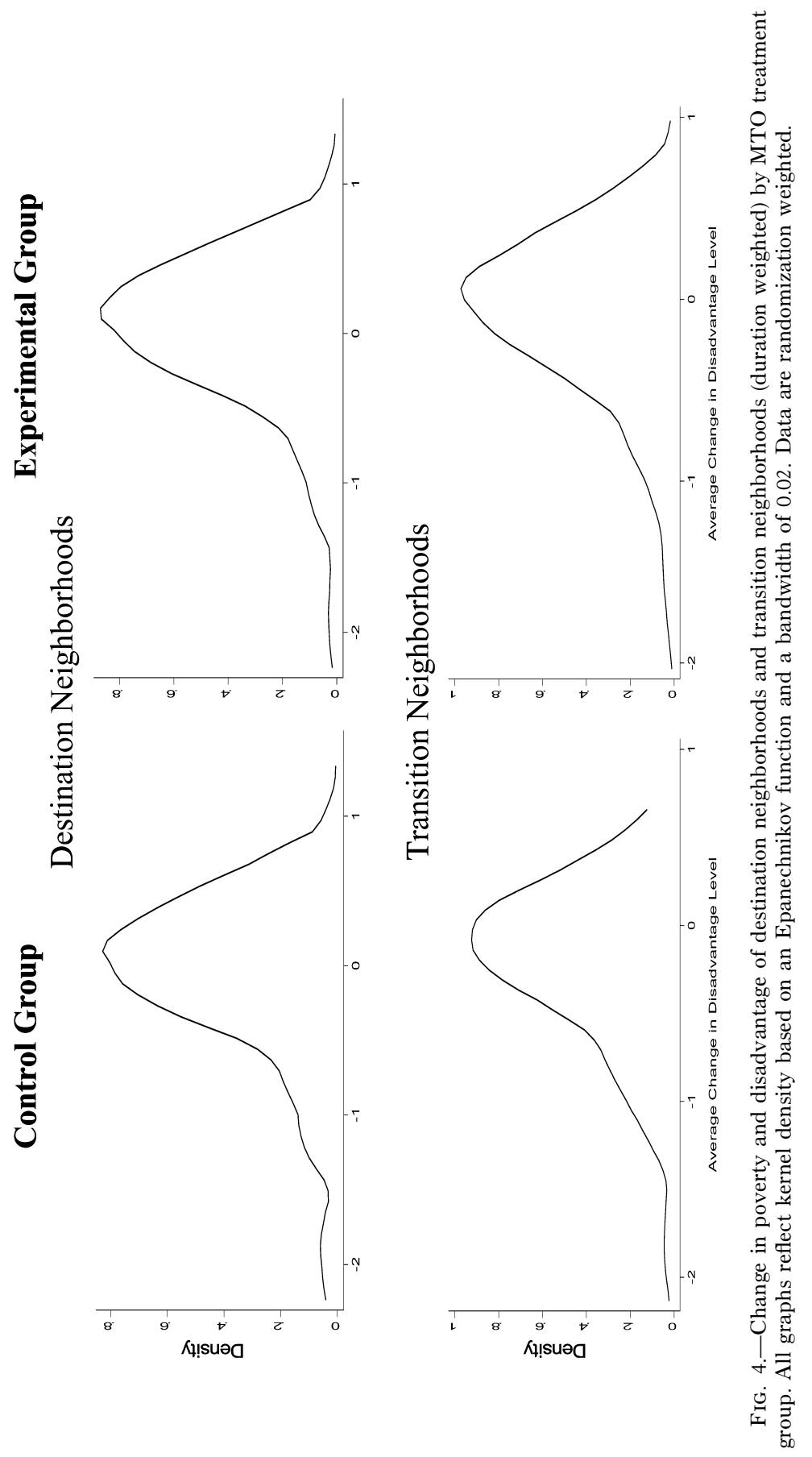


American Journal of Sociology

both destination and transition neighborhoods. A close similarity across treatment groups is revealed, especially for disadvantage. I also examined change from 1995 to 2002 in the measures of neighborhood social processes noted above (e.g., cohesion and control), and I found that no change trajectory differed significantly by treatment group. These results are consistent with neighborhood employment change (Kling et al. 2007, web appendix, table F14), further confirming a lack of MTO effect on contextual dynamics.

\section{SPATIAL DISADVANTAGE}

Although the unit of ecological analysis is not highlighted by either CM or Ludwig et al., the spatial proximity of disadvantage nonetheless bears directly on the debate. A number of social analysts have noted that African-Americans face a unique risk of ecological proximity to disadvantage that goes well beyond local neighborhoods, including blacks in the middle class. This point is vividly made in Black Picket Fences: Privilege and Peril among the Black Middle Class (Pattillo 1999) and highlighted in work showing the spatial disadvantages of black middle-class (and working-class) neighborhoods compared to internally similar white areas (Sampson et al. 1999). The implication is straightforward: while the black poor might be able to move to a better-off census tract with an MTO voucher, that tract is still likely to be embedded in a larger area of poverty and, therefore, spatial disadvantage. Moreover, prior research has shown evidence consistent with spillover effects or spatial contagion at lower units of analysis. Tracts are not only relatively small in size, they are governmentally defined with ecological borders many have criticized as artificial and highly permeable (for more discussion, see Hipp [2007]).

It follows theoretically that we need to consider more than just census tracts in any adjudication of MTO. I do so by taking advantage of the fact that in Chicago, as elsewhere, local community areas exist that have well-known names and fairly distinct borders such as freeways, parks, and major streets-especially in comparison with census tracts. Chicago has 77 such areas, with average population of about 37,000 persons, that were defined many years ago to correspond to socially meaningful and natural geographic boundaries. Although some of these names and perhaps even boundaries have undergone change over time, Chicago's community areas are still widely recognized by administrative agencies, local institutions concerned with service delivery, and residents alike. They also have distinct names that are widely used (e.g., Hyde Park, Grand Boulevard, South Shore, and Lincoln Park). Community-area boundaries have political force and symbolic value that continues (Suttles 1990). It is rel- 
MTO Symposium: Moving to Inequality

evant to remember as well that Wilson's (1987) thesis of concentration effects was developed using community areas in Chicago as the empirical unit of reference (see, e.g., his seminal chap. 2). I therefore recalibrated the movement in MTO by characteristics of community areas, relying on the finding that the vast majority of moves of both experimental and control group members are clustered within Chicago (see also fig. 2).

Figure 5 displays the spatial network of connections outward from the MTO baseline, per figure 1. As before, I seek the big picture on differences in outcome-in this case, community-level concentrated disadvantage, split into equal thirds (low, medium, and high) based on the Chicago distribution. What we see again, although in a new light, is a striking social reproduction of disadvantage among MTO participants, experimental and control group members alike. ${ }^{15}$ The patterns of neighborhood attainment flows in the two groups are indistinguishable, suggesting a profound structural constraint.

A nonparametric way to further assess this idea is to calculate the number of families each Chicago community area "received" from the experimental and control groups and then calculate the Spearman's rankorder correlation. The resulting rank-order correlation is .79 $(P<.01)$. Hence, when we direct our attention to the pure experimental comparison induced by MTO, we find that both groups not only ended up in very similar disadvantaged communities, they largely moved to the same exact communities. At some point, then, when we consider the broader notion of spatial disadvantage and see locations converging, individual neighborhood measures become less relevant. ${ }^{16}$ Clustering is surprisingly present even at the tract level for both groups. Over half $(55 \%)$ of the experimentals ended up in just $4 \%$ of all possible tracts in the Chicago metropolitan area, while $55 \%$ of the control group ended up in $3 \%$ of all tracts. This analytic approach reveals the limits of focusing only on treatment-induced differences and not examining the sorting of MTO participants to all potential outcomes in the ecological network sense. In network terms, the strong spatial concentration indicates the centrality of a rela-

\footnotetext{
${ }^{15}$ I selected a random sample of the experimental group to equalize sample sizes and to make for a balanced and easier-to-see comparison. Using the full sample produces a similar pattern.

${ }^{16}$ As for census tracts, $t$-tests for the differences by treatment group were examined at the community-area level for the eleven survey-based social processes independently measured in PHDCN, by both level and change. There were no significant differences. I also examined spatial "neighbors of the neighborhood" at the census-tract level by calculating the spatial lag of poverty and disadvantage using a Euclidean distancebased measure - the average of neighboring tracts weighted by distance from the focal tract. Neither spatially lagged poverty nor concentrated disadvantage were significantly different between experimentals and controls. At destination, the magnitude of difference in spatially lagged percent poverty was less than 1.5 percentage points.
} 


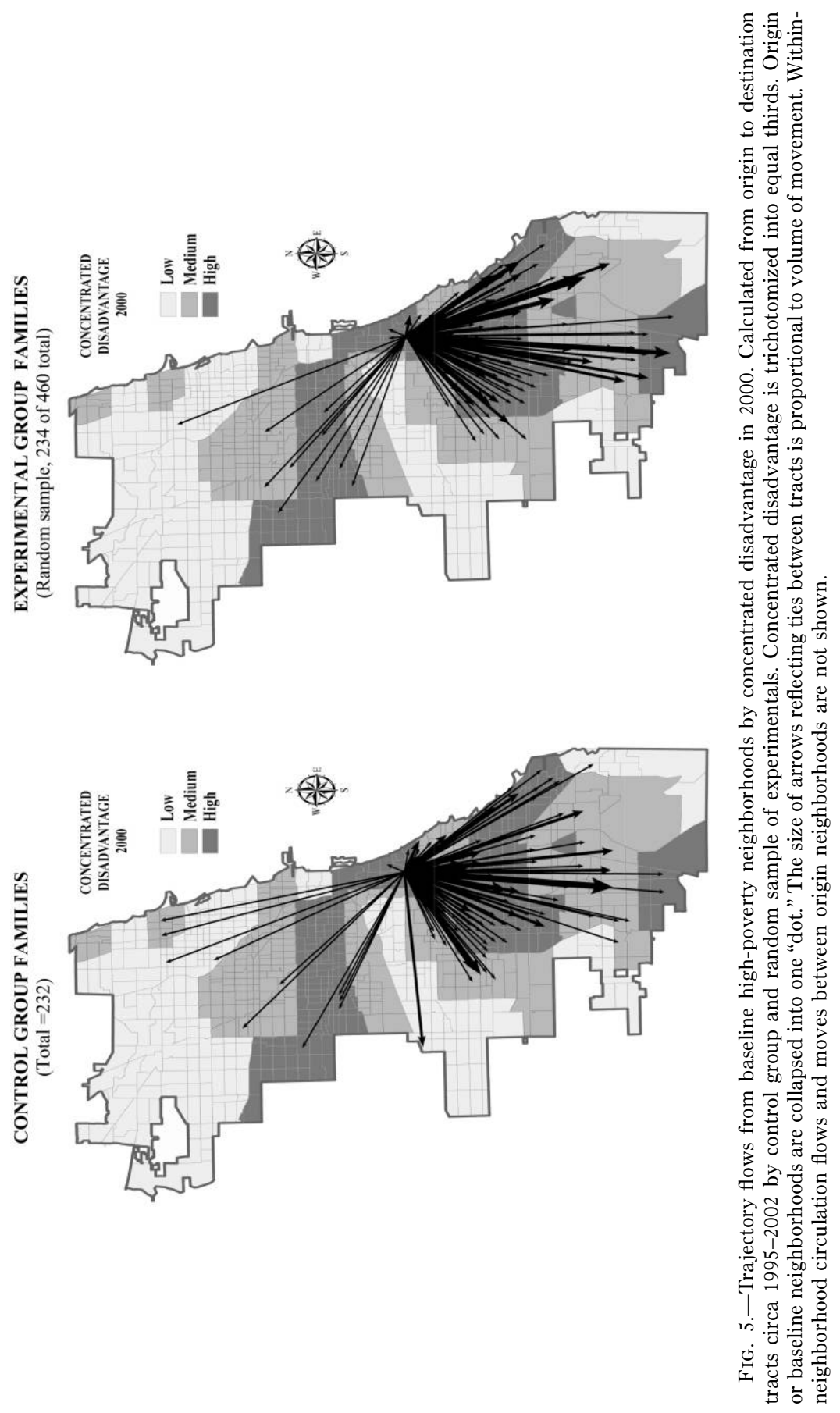


MTO Symposium: Moving to Inequality

tively small core of neighborhoods that receive the majority of MTO families, regardless of treatment or compliance status. Hence, one way to think about the pattern of mobility is that there is a community-vacancylike chain to the movement of the poor.

The data to this point show that sorting in MTO is highly structured ecologically. Poor people moved to inequality, with opportunities embedded in a rigid and likely reinforcing dynamic of metropolitan social structure. The replicating nature of moving decisions in MTO prompts a reconsideration of the typical ways of viewing selection bias and compliance in the experiment.

\section{NEIGHBORHOOD SORTING AS A SOCIAL PROCESS}

It is often remarked how difficult it is to get a family to consent to move out of the slum no matter how advantageous the move may seem from the material point of view, and how much more difficult it is to keep them from moving back into the slum. (Zorbaugh 1929, p. 135)

Humans are agents with the decision-making power to accept or reject treatments (Heckman and Smith 1995). Statistics on the "take-up" rate show that a majority of MTO families who were offered a voucher did not actually use it. Families who did use the voucher experienced less neighborhood poverty in comparison with the noncompliers, but the vast majority remained within a relatively short distance of their origin neighborhood. Moreover, many families moved back into poor neighborhoods that were very similar to the ones in which they started, surprising many observers. Yet no one should be surprised at these facts. Back in the 1920s, Zorbaugh (1929) noted the "pull" of the slum and how the strong nature of its social ties kept people returning. It is only from a middleclass point of view, or what Zorbaugh called the "budget-minded social agency" (1929, p. 134), that the behavior of those who have grown up in poverty seems "incalculable."

$\mathrm{CM}$ argue that this self-selection, particularly within the experimental group, poses problems for valid causal inference. For one, the "intent to treat" effect will significantly underestimate the "treatment effect on the treated," or the effect of actually moving. To cope with this challenge, Ludwig et al. propose the randomization of being offered a voucher as an instrumental variable to identify the impact of actually using the voucher. Valid causal inference depends on the exclusion restriction that the offer of a voucher will affect outcomes only if participants use the voucher. On first consideration, this seems plausible in MTO, supporting the validity of inferences about the treatment effect on the treated (or 
American Journal of Sociology

"compliers")- those who would use the voucher if assigned to the experimental condition but who would not use the voucher if assigned to the control group. By weighting according to proportion compliers, Ludwig et al. argue that the unbiased effect of the bundled MTO treatment (combining moving with neighborhood context) can still be estimated, and they show us how to do so in a cogent manner that I expect will continue to be used in future analyses of MTO.

$\mathrm{CM}$ further argue that the more time one spends in poverty, the greater the neighborhood effect is likely to be, which leads them to conduct an analysis of time spent in poverty, controlling for treatment-group status and background factors. In other words, CM perform an analysis that relies on the observational component of MTO data and a regression analysis design. Ludwig et al. critique their method on the grounds that it introduces hidden (or, perhaps better put, unknown) selection bias. Their solution is to use the randomization of vouchers as the instrument (interacted with site) this time for the duration-weighted poverty rate, a technique they again cogently explain. Ludwig et al. also argue that those randomized at a later date in the initial baseline period are by definition subject to a different window of exposure. Accounting for these cohort differences and capitalizing on the random assignment, overall Ludwig et al. find no treatment effects of duration in poverty on adult economic self-sufficiency. They correctly note that in this sort of estimation, the results cannot literally be interpreted as the effects of neighborhood poverty on outcomes, but are rather the bundle of factors associated with poverty. The multiple characteristics correlated with poverty, such as percent black, could not be simultaneously instrumented because of lack of statistical precision.

My take here is mixed. First, I think CM have done the field a service by emphasizing the importance of cumulative exposure and the need to model the duration of time spent in poverty. Yet the assumptions needed to support their regression framework have been properly criticized: while CM's basic idea may be theoretically justified, the baseline variables available in MTO and its limited developmental or time-varying measures mean that selection bias is still potentially a problem, as CM themselves note (pp. 138-39). Thus, in principle I find the Ludwig et al. argument that "instrumenting" is the preferred way to go correct, especially given the availability of a randomized voucher. I also agree that cohort differences in randomization should be adjusted because they reflect differences in experienced time in poverty.

Second, however, the instrumental variable (IV) method is imperfectnot only because duration in poverty cannot be isolated as the cause, but because of $(a)$ potentially unwarranted assumptions one must make about social interactions and $(b)$ the fact that moving itself is part of the causal 


\section{MTO Symposium: Moving to Inequality}

pathway: the MTO design was not set up to experimentally estimate the separate effects of moving and change in poverty. ${ }^{17}$ The latter point is particularly relevant given evidence that moving is a major life event that predicts later behavior (Hagan et al. 1996). There may also be mobility-by-neighborhood interactions, perhaps explaining the gender differentials (e.g., over time boys might be more affected by breaking off prior networks or being the new kid in the neighborhood). For this reason, $\mathrm{CM}$ are not unwise to want to separate moving or compliance status from the effect of poverty, which their models implicitly try to do. Kling et al. (2007, pp. 98-99) recognized this point and entered complier status as a control variable in an IV regression analysis.

In short, $\mathrm{CM}$ are right to want to learn about selection and not just dismiss it as noise, as most experimentalists do. In a welcome move, Ludwig et al. (p. 176) signal openness to a better understanding of selection. A renewed appreciation of selection processes is thus in order.

\footnotetext{
${ }^{17}$ If social interactions among MTO participants are implicated in voucher use and neighborhood outcomes, such "interference" violates SUTVA, the stable unit treatment value assumption (Sobel 2006). As Ludwig et al. argue, the interference concern is mitigated by the small sample of MTO participants in destination neighborhoods. Nonetheless, the latter are still spatially concentrated, suggesting that if MTO-like experiments were taken to scale, interference among units might be formidable. But even in the original experiment, it would seem that the more relevant concern is the strong clustering in origin neighborhoods (fig. 1). Suppose I were a complier and moved further south in Chicago (figs. 2 and 5) to satisfy the voucher requirement. If I or my children had friends or family back in the old neighborhood who were voucher eligible, and we complained about the hardship of moving or, to the contrary, expressed enthusiasm about the new neighborhood, these social interactions could have influenced the moving decisions or destinations of those in our network-especially given the multiyear window of randomization (and thus lease-up) and the fact that many compliers drifted back to poor neighborhoods. Ludwig et al. assume that the intervention had no effect on noncompliers and that interference is unlikely because "fully 55\%" reported no friends in baseline neighborhoods (p. 155). But of course this means that $45 \%$, or nearly half, did have friends in the neighborhood (35\% had family), and my calculations suggest that approximately $20 \%$ of the core residential population at baseline was in MTO, a nontrivial saturation level. Moreover, there is a large and significant difference in compliance- $42 \%$ vs. $25 \%$ - between late and early randomization groups. It is unclear why later cohorts were so much more likely to lease up. The MTO nonprofits were apparently more effective in counseling as time went on, but the pattern is also consistent with social interactional or linked migration flows. Whether compliers communicated their likes/dislikes or otherwise interacted with other MTO members is ultimately unknown, so we have to assume social independence to go the IV route. Further research is needed to sort out the consequences of the large cohort differences in lease-up and possible interdependent social interactions. It should be noted too that the poverty-induced differences in MTO, at least in Chicago, are driven by the late and not the early cohorts.
} 
American Journal of Sociology

Turning Selection Around: The Causes of Effects

Relying on randomization as valorized by the experimental paradigm, even if logistically possible, as in MTO, brackets knowledge of how causal mechanisms are constituted in a social world defined by the interplay of structure and purposeful choice. Yet most nonexperimental research on neighborhood effects is just as guilty of failing to confront directly and achieve a basic understanding of the social processes that select individuals into neighborhood "treatments" of interest (see also Heckman 2005). Although the claim is not articulated in quite this way, the MTO debate suggests that the goal of studying sorting and selection into neighborhoods of varying types is an essential element in the larger theoretical project of understanding neighborhood effects.

Patrick Sharkey and I recently pursued such an agenda and in addition focused on the social consequences of residential selection (Sampson and Sharkey 2008). Our question became how individual mobility decisions combined to create spatial flows that define the ecological structure of inequality, an example of what Coleman (1990, p. 10) more broadly argued is a major underanalyzed phenomenon-micro-to-macro relations. Analyzing longitudinal trajectories of Chicago residents (again using PHDCN) no matter where they moved in the United States, we found results that suggest several implications for understanding neighborhood change and, thereby, neighborhood effects.

First, a number of previously unobserved factors that represent hypothesized sources of selection bias in studies of neighborhood effects were, despite the litany of suspicions raised in the MTO literature, of surprisingly minimal importance in actual or revealed neighborhood selection decisions. Residential stratification closely follows racial/ethnic lines and socioeconomic position, especially in terms of income and education. These are for the most part the only surviving factors that explain a significant proportion of variance in neighborhood attainment. Even after we introduced a variety of theoretically motivated covariates that captured largely unstudied aspects of locational attainment-such as depression, criminality, and social support-the substantive picture of our results was unchanged. It follows that longitudinal studies accounting for neighborhood selection decisions and a fairly simple yet rigorous set of individual and family stratification measures may make for a reasonable test of neighborhood influences. ${ }^{18}$

${ }^{18}$ At some point, the burden is on the "unobserved heterogeneity" theorists to posit a coherent, plausible, and nonmysterious explanation of the individual differences accounting for stratification outcomes that add up to a substantial confounding of the long and by now quite exhaustive list of suspects that have in fact been studied. I would add that, despite accounting for changes in income, marital status, household 
MTO Symposium: Moving to Inequality

Second, whites and Latinos living in neighborhoods with growing populations of nonwhites were more likely to exit Chicago, providing evidence that realized mobility arises, at least in part, as a response to structural changes in the racial mix of the origin neighborhood. The same is not true of black families - the data suggested that it is not African-Americans' preference for same-race neighbors that seems to matter so much as whites' and Latinos' eagerness to exit neighborhoods with growing populations of blacks. Ironically, then, neighborhood conditions appear to matter a great deal for influencing neighborhood selection decisions, suggesting a different kind of neighborhood effect: sorting as a social process.

MTO might be seen by CM as a failure in terms of treatment strength, but if there is any failure, these results suggest it is one of society. Indeed, no matter where individuals choose to live, and no matter what their background or the reasons behind their decisions, the racial income hierarchy of neighborhoods is rendered durable (Sampson and Sharkey 2008). The flow analyses in figures 2 and 5 suggest that MTO moves are no different. Hence, while CM's methods may be limited, a deeper point emerges: in examining the sources and social consequences of residential sorting, we need to conceptualize neighborhood selection not merely as an individual-level confounder or as a "nuisance" that arises independent of social context (see also Heckman 2005; Bruch and Mare 2006). Instead, neighborhood selection is part of a process of stratification that situates individual decisions within an ordered, yet constantly changing, residential landscape.

To demonstrate this idea further, figure 6 displays the moves of black and white families in PHDCN during the period of the MTO study. These families all have children under 18, as in MTO, but they were not selected on the basis of poverty status. For parsimony, I present just the moves of black and white families. Ties between census tracts are valued in proportion to volume, and again the shading denotes the level of concentrated disadvantage in each community area. Despite the different sample sizes, whites and blacks form dynamic connections among neighborhoods within what appear to be different parallel universes: there is almost no racial exchange across areas, and black families move within

size, and several other time-varying factors, my recent study with Sharkey (Sampson and Sharkey 2008) explained only about $10 \%$ of within-family change in neighborhood conditions occurring over the course of the study. Individual characteristics, changes in life circumstances, and forces like "initiative" only go so far in explaining neighborhood stratification such as that shown in fig. 5. This point is reinforced even more when mechanisms of the intergenerational transmission of neighborhood disadvantage are considered (Sharkey 2008). 


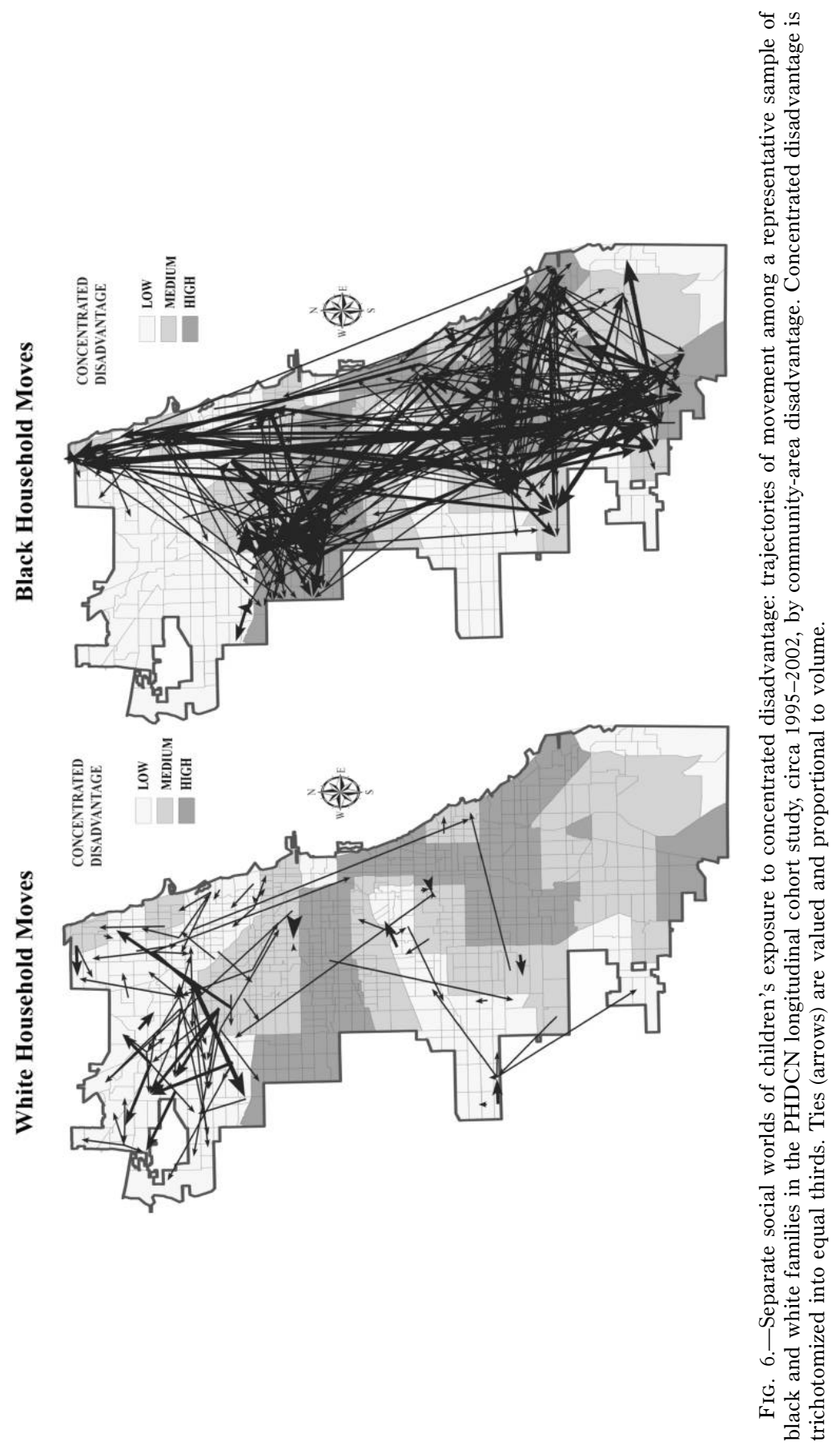


MTO Symposium: Moving to Inequality

sections of the city that are highly circumscribed by concentrated disadvantage.

Figure 7 repeats the analysis on MTO "equivalents" and shows "churning" flows within neighborhoods. The origin community of MTO is captured by PHDCN on the near South Side. We see considerable circulation within that poor sector as well as moves further south to other disadvantaged neighborhoods, a pattern similar to the MTO flows. A westside cluster and a far north-side cluster are also observed. In general, then, the hierarchy of places is rendered durable in both studies. Chicago is only one city, of course, and its take-up rate was lowest among MTO sites, but the basic pattern holds in the Baltimore MTO study (Clark 2005) and I would hypothesize similar patterns elsewhere. At the national level, Sharkey (2008) has shown the intergenerational transmission of concentrated disadvantage, further demonstrating the durable lock that segregation by race and class has on trajectories of neighborhood attainment.

\section{DEVELOPMENTAL NEIGHBORHOOD EFFECTS}

My final set of analyses returns to the idea that neighborhoods have the potential to alter developmental trajectories, but their influence may be set at critical junctures. To illustrate this process, I consider the lagged effect of concentrated disadvantage on trajectories of verbal ability (Sampson et al. 2008). The implications for MTO are twofold, bearing on relevant counterfactuals for the effects of concentrated disadvantage and developmental-neighborhood interactions.

Consider first the analytic implications of the clustering of disadvantage for attempts to estimate neighborhood effects at the individual level. When concentrated disadvantage was defined (Sampson et al. 2008) as falling in the upper quartile of the scale distribution (i.e., high disadvantage) across all Chicago census tracts (the origin of the PHDCN sample), the startling result was that no whites and only a few Latinos lived in disadvantaged neighborhoods across three separate time points, making it impossible to reliably estimate treatment effects of disadvantage for these groups. When treatment was defined using the top quartile of the national distribution of concentrated disadvantage, a different problem occurred: virtually all blacks (97\%) were exposed. When the treatment was instead defined as living in a neighborhood with more than $30 \%$ poverty, at most $5 \%$ of whites were exposed at any given time.

The difference between exposure to neighborhood poverty and the more comprehensive measure of concentrated disadvantage is dictated by the nature of ecological confounding. Conditional on being exposed to high- 


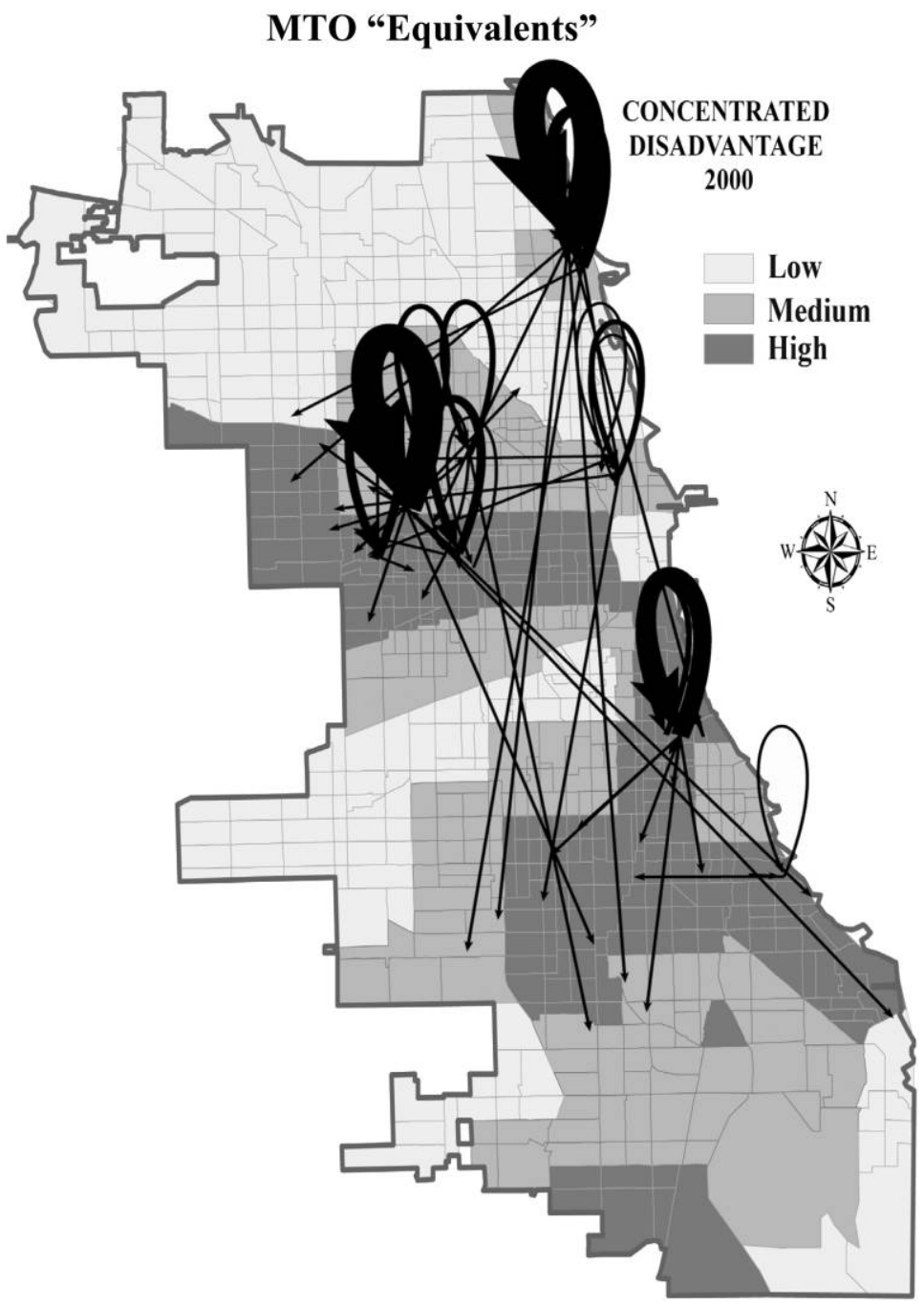

FIG. 7.-Neighborhood circulation flows of "MTO-equivalent" households in the PHDCN longitudinal cohort study $(N=139)$, circa $1995-2002$, by concentrated disadvantage in Chicago community areas. Mobility ties between census tracts are proportional to volume, and "loop" arrows depict internal moves within the baseline neighborhoods of origin. Concentrated disadvantage is trichotomized into equal thirds. 
MTO Symposium: Moving to Inequality

poverty ( $>30 \%$ ) neighborhoods at baseline, black children were still much more likely to live in segregated areas characterized by welfare dependency, unemployment, and female-headed households. For example, the unemployment rate is over $50 \%$ higher in poor areas where blacks live in comparison with those where whites live, and there is a qualitatively different racial composition as well—-three-quarters black versus less than one-third. The stratification of America's urban landscape by race and class once again reveals that concentrated disadvantage is a different treatment than simple poverty and one experienced almost solely by Chicago's black population.

The second implication concerns lagged effects and developmental interaction. Building on recent work on neighborhood selection (Sampson and Sharkey 2008; Sampson et al. 2008), I use PHDCN data to formulate a cross-classified multilevel model designed to estimate the effects of concentrated disadvantage on verbal ability, a case in which the contextual treatment, outcome, and confounders all potentially vary over time (Robins 1999; Robins, Hernán and Brumback 2000; Hong and Raudenbush, in press). Information gleaned from analysis of residential selection through time is used to weight each person-period observation by the inverse probability of receiving the treatment (disadvantage) actually received (for details, see Sampson et al. 2008, p. 847). On the basis of this model, it is estimated that concentrated disadvantage deflects later gains in verbal ability among African-American children by over 4 points, over $25 \%$ of a standard deviation and roughly equivalent to missing a year of schooling (Sampson et al. 2008, p. 852). Neighborhood effects on verbal ability therefore appear to linger on even if a child leaves a severely disadvantaged neighborhood.

Theoretically, we would expect that influences on verbal skills would be most pronounced during the developmentally sensitive years of childhood (Shonkoff and Phillips 2000). I test this developmental interaction by estimating the influence of neighborhood disadvantage on verbal ability for the youngest African-American children assessed in the PHDCN cohorts-6- to 9-year-olds at baseline. Figure 8 presents these new point estimates for four neighborhood treatment sequences. There is now a 6point deficit in verbal ability trajectories linked to living in disadvantage at the midpoint ("wave 1 ") of the study $(t=2.74 ; P<.01)$. When including 12 -year-olds there is also a significant cohort-by-treatment interaction. If we assume for the sake of the current argument that the selection model is reasonable and that the Robins inverse probability of treatment weighting (IPTW) method adjusts for baseline (wave 0) and time-varying confounding, the implications for MTO are significant. Specifically, consider trajectories of verbal ability for black children who lived in concentrated disadvantage at wave 1. Extending the argument of Sampson et al. (2008, 


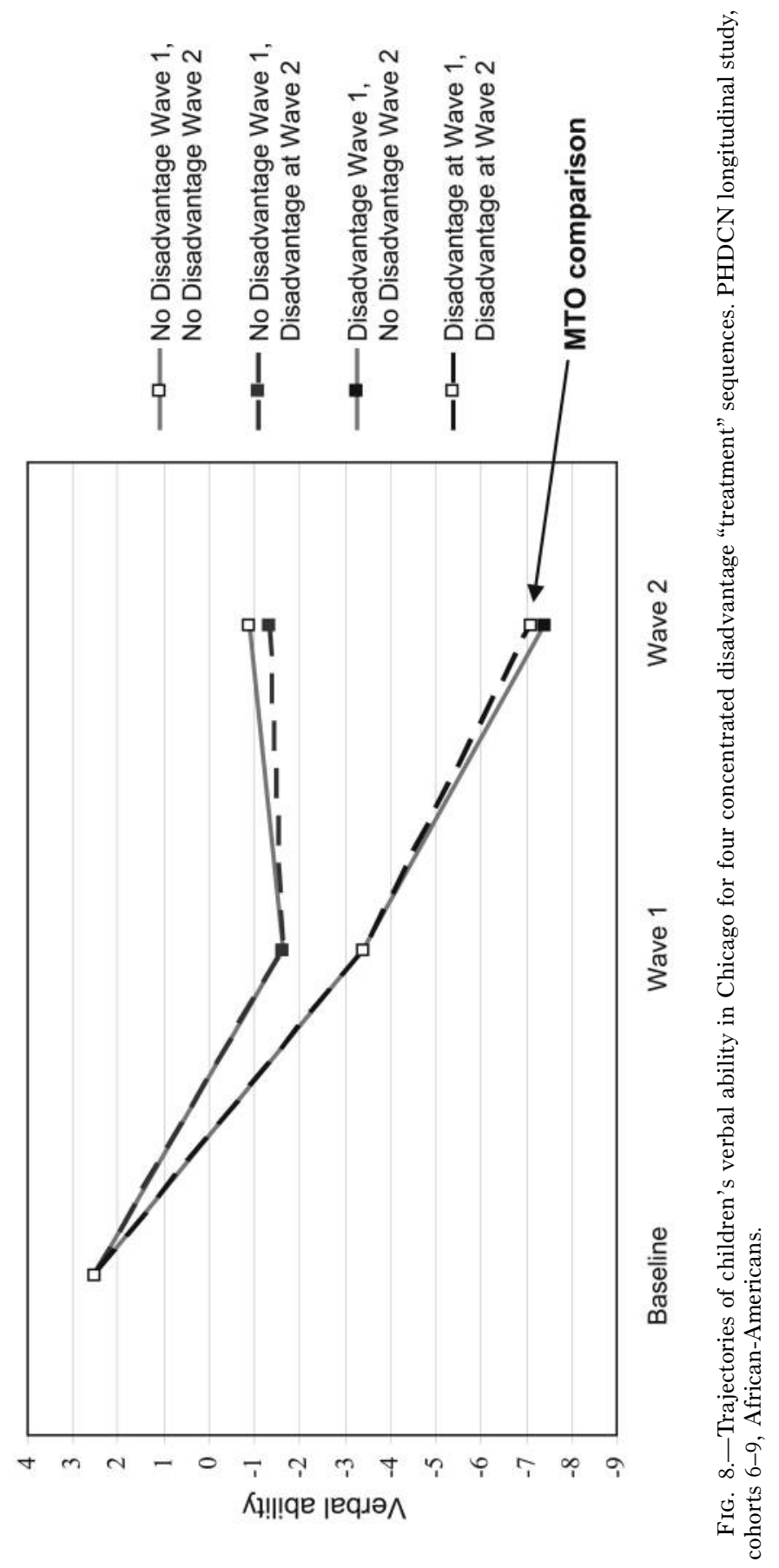


MTO Symposium: Moving to Inequality

p. 852), if we randomly provided housing vouchers to this group and compared outcomes at wave 2 , we might conclude that there are no neighborhood effects because there is no difference between experimentals and controls at wave 2 among those receiving treatment in wave 1 (compare the bottom two lines in fig. 8). This conclusion would be incorrect, however, because it brackets the significant and substantial lagged effect of living in concentrated disadvantage, as compared to advantage (the top two lines in fig. 8), at wave 1 (a 6-point "IQ" effect). Note also that the concurrent disadvantage effect is not significant.

It follows that MTO-type studies of adolescents who grew up in poverty may not provide a robust developmental test of the causal effect of neighborhood social contexts. To be sure, one can examine developmental interactions in MTO, but the design sets limits on how far one can push in this direction-only $14 \%$ of the interim evaluation sample was between the ages of 5 and 7 . Fully over half were age 12 or older. This, combined with the crucial fact that MTO families were selected on poverty, means that analyses like those in figure 8 are constrained by design. On the positive side, however, informative models of selection can still be applied to MTO. Revising CM's intent, one could directly model duration of exposure to poverty, including residential moving history and complier status, late cohort randomization, and changes in life circumstances that may have influenced moves back into poverty. The resulting probabilityof-treatment estimates could then be incorporated into a neighborhood causal analysis, especially for the youngest children. It is unclear whether properly specified dynamic models will (or should) come to the same conclusion as the IV approach, and I am making no claims for marginal structural models as a panacea. One would have to make assumptions that could never be proven, including that unobserved covariates that predict outcomes are unrelated to treatment-group assignment conditional on observed confounders. But the MTO instrument for duration requires assumptions, too, and is fallible for quite different reasons. It therefore seems that both sides stand to gain from learning more about the nature of selectivity in MTO, and that time-varying counterfactual methods can be exploited to push the question farther than it has gone to date (see also Morgan and Winship 2007).

\section{SUMMARY}

At issue is one of the best controlled social science experiments-if not the best-ever conducted in a natural setting. Yet scholars disagree sharply on its evaluation. This seems to me an intolerable situation because it invites general contempt for social science research, especially from the courts, who 
American Journal of Sociology

ever more frequently are asked to accept social science research as evidence. If the professors cannot collate their interpretations, the prestige of social science is bound to suffer. For that reason, I would consider it a fitting ending to this debate if the following points might constitute, as I hope, a fair summary. (Zeisel 1982b, pp. 395-96)

Interestingly enough, just over a quarter-century ago $A J S$ hosted a similar symposium on proper methods of causal analysis for a major randomized trial in the social sciences. The arena was criminal justice, and the issue at stake was whether prisoners fared better or worse with financial payments upon release. One side proposed CM-like regression adjustments to answer the causal question (Rossi, Berk, and Lenihan 1980), whereas Hans Zeisel, Ludwig et al.'s counterpart of the day, insisted on a pure and simple comparison of experimentals with controls (Zeisel 1982a). The details are not important now, but how Zeisel concluded the debate, as quoted above, is. MTO today is-rightly, I believe-the gold standard for experimental social science at the individual level, and it would be a shame if the 2008 experimental debate ended in confusion. Like Zeisel, I believe it is essential that we get social experiments right.

With that in mind, and taking a cue from Zeisel, let me humbly propose something on the order of a summary closing to this particular debate. It is my hope that both sides might agree and that my intervention points to a constructive agenda for the future. If so, we should be grateful to the authors for their collective efforts and to the journal for pushing the field to think harder.

1. Benefits of experimental design.-MTO is a major contribution to the long tradition of experimental social science. By introducing a randomized design that induces the poor to make residential moves to lowerpoverty neighborhoods, MTO eliminates "selection bias" on unobservables as a confounding explanation of neighborhood effects on individuals. Given ethical, pragmatic, and institutional concerns that render social experiments rare, the design is ingenious.

2. Limits on MTO question and generalizability.-By design, MTO was an individual-level intervention that offered housing vouchers to extremely poor, largely minority families. Therefore, nothing can be inferred from MTO about the success or failure of neighborhood-level interventions, and any generalizations about voucher effects are restricted to an important but small segment of the population.

3. Mixed results.-At the individual level among the poor, MTO has demonstrated mixed results that vary by outcome, site, and subgroupespecially gender. Some effects are large (e.g., those on mental health and girls' behavior), while others, like adult economic self-sufficiency, appear null. In this sense MTO has been important in debunking simple-minded 
MTO Symposium: Moving to Inequality

hypotheses: no simple conclusion can or should be drawn about neighborhood effects in the abstract.

4. Strength of treatment.-The treatment of the MTO voucher induced statistically significant reductions in census-tract poverty (about 8 percentage points overall) in comparison with the control group, but within what are usually considered high-poverty areas and (at least in Chicago) only for the later randomization cohorts. While over half of the families who used a voucher to move through MTO ("compliers") had tract poverty rates of approximately $20 \%$ in 2002 , the average poverty rate was greater than $30 \%$ for both the experimental and control groups overall across sites. MTO thus induced neighborhood differences mainly of degree, not kind. There are also significant cohort interactions that need further study.

5. Beyond poverty.-There were even smaller differences induced by MTO in concentrated disadvantage, defined as the segregation of AfricanAmericans in neighborhoods of resource deprivation across multiple domains (fig. 2). Moreover, whether we look only at destination neighborhoods or take into account interim moves, the racial context of both controls and experimentals was still hypersegregation-nearly identical for both groups.

6. Neighborhood counterfactuals by race.-Because of this intersection of poverty, race, and family structure-in Chicago as in many U.S. citiesthere is no counterfactual for whites (as implicitly assumed in many studies), and therefore neighborhood effects of concentrated disadvantage are undefined for them. Independently, both the MTO and PHDCN studies portray, in different ways, this structural reality.

7. Neighborhood trajectories and social processes.-There were no significant differences in the rate of change for poverty or for a host of neighborhood-level social processes (e.g., cohesion, closure) in Chicagowhether static or dynamic - by randomization group. As a result, the trajectories that destination neighborhoods were on turned out to be virtually identical for experimentals and controls, and social organizational features of community were largely unaffected by treatment. The significance (or lack thereof) of differences does not change when complier status is adjusted.

8. Spatial proximity and flows of disadvantage.-Experimental and control families ended up in the same or similar larger community areas. The patterned structure of community-level ties induced by moving, seen in the "bird's-eye" view of Chicago (fig. 5), reveals a near-identical network across experimentals and controls. Moreover, community-area differences in social processes were not different by treatment group, nor was spatially lagged poverty or concentrated disadvantage.

9. Causal significance of moving.-By design, the MTO experiment 
American Journal of Sociology

induces neighborhood change by moving, itself a life-course event of theoretical significance. Hence, moving and context are intertwined.

10. Developmental neighborhood effects.-Because MTO subjects were selected on living in neighborhood poverty, which is durable, early developmental effects of concentrated poverty cannot be effectively studied for adults and only in a limited way for children. For the most part, MTO tests whether exits from poverty can overcome previously accumulated deficits. Thus, any lack of MTO effects does not imply a lack of durable or developmental neighborhood effects.

11. Urban dynamics.-Moves of a random sample (PHDCN) reproduce concentrated inequality and suggest the urban dynamics that would result if MTO-like programs were taken to scale. White and Latino flight also means that the treatment is not constant and that the intervention itself may induce further neighborhood changes and, by implication, the concentration of disadvantage.

12. Social interactions.-Using randomization as an instrumental variable requires that we invoke assumptions about voucher use, some of which, like noninterdependence of social interactions in the experiment, are open to question for acts of moving. If we assume no interference among units in MTO (see n. 17), we can estimate poverty-linked (or "bundled") neighborhood duration effects, per Ludwig et al.'s approach. But if migration research has taught us anything, it is that moving is embedded in chain-like social networks. Selection processes should therefore still be pursued as CM started to do, perhaps most effectively using time-varying counterfactual methods that exploit information on selection into neighborhood treatment. Because moving is a competing causal pathway in the duration-weighted models, counterfactuals are likewise needed to estimate and compare the effects of moving.

13. Follow-up.-Perhaps surprisingly, given the specific nature of the MTO treatment in a constrained urban structure, there is still evidence of neighborhood effects (point 3) that needs further unpacking. Even modest relative reductions in neighborhood poverty predict improvements in mental health and girls' behavior, which over time can cumulate to shape life outcomes. By following the youngest MTO children further in time, one can also gain more leverage on developmental interactions, albeit conditioned on poverty. Overall, I would conclude that the planned followup of MTO is a scientifically crucial investment.

14. Causes and mechanisms.-When randomization at the individual level is invoked and we find evidence for the influence of a voucher offer on individual outcomes, it remains unclear what mechanisms link the manipulated treatment with outcomes. Experiments do not answer the "why" question. The causes of neighborhood effects and social mecha- 
MTO Symposium: Moving to Inequality

nisms have been a black box, and neighborhood-level interventions have been neglected.

15. Social structure and selection.-In the social structure that constitutes contemporary cities, selection bias is misleadingly thought of mainly in terms of unobserved heterogeneity and statistical "nuisance." Selection is a social process that itself is implicated in creating the very structures that then constrain individual behavior. MTO can be exploited to further study the causes of neighborhood effects and the aggregate consequences of movement for social inequality.

If this is a reasonable summary and consensus is achieved, the burden can now be lifted from MTO as the judge and jury of neighborhood effects writ large. Indeed, the validity of MTO depends on the question one wants answered. As a century or more of urban sociology reveals, neighborhood effects may be conceived in multiple theoretical ways at multiple levels of analysis and at varying time scales of influence. No one design captures the resulting plethora of questions.

Coda

Experiments have long been cloaked in the mantle of science because of their grounding in the randomization paradigm, the putative cure for the ills of selection. If anything, the lure of experiments is increasing in the social sciences, with new journals and societies sprouting widely in recent years and funding decisions that favor the experimental method falling in line. ${ }^{19}$ In the field of neighborhood effects, the belief that experiments are "a superior research strategy" for assessing causality is also fast becoming a mantra (Oakes 2004, p. 1929). As important as experiments are, however, they have tended toward individual reductionism and have obscured the causes of effects and operative social mechanisms. Any deep understanding of causality requires a theory of mechanisms no matter what the experiment or statistical method employed. Estimation techniques, in other words, do not equal causal explanatory knowledge (Heckman 2005; Morgan and Winship 2007).

But theories and models are not enough, either. I wish to conclude with a plea for the old-fashioned but time-proven benefits of theoretically motivated descriptive research and synthetic analytic efforts. After all, ob-

\footnotetext{
${ }^{19}$ Criminology, epidemiology, and neighborhood effects seem particularly affected. There is, e.g., a new Academy of Experimental Criminology, a new Journal of Experimental Criminology, and the latest Stockholm Prize for scientific criminology was awarded for experimental work. The promotion of experiments has once again become a contemporary cause. Ironically, however, in fields like social psychology where the experimental paradigm has long reigned, experiments have recently come under sharp criticism (Brannigan 2004).
} 


\section{American Journal of Sociology}

servational research will continue to be the workhorse of social science, so we might as well get it right, too. Experimentalists often forget that some of the most scientific theories around-Darwin's natural selection being just one example-were derived from systematic observation interacting with theory. Lieberson and Lynn (2002) argue that sociology has lost its way in trying to mimic a classical physics-like focus on determinism, whereas instead we should think more like evolutionary biologists. As they note, Darwin's theory was constructed not in a lab or using an experiment but with methods much like those available to social scientists-by "drawing rigorous conclusions based on observational data rather than true experiments" and by means of "an ability to absorb enormous amounts of diverse data into a relatively simple system" (Lieberson and Lynn 2002, p. 1). Many causal conclusions, including the consensus that smoking causes cancer, have come about after years of careful observational research linked to rigorous thinking about causal mechanisms. The early discovery of penicillin and the cause of cholera outbreaks were similarly observation based.

Descriptive data, mapping, and pattern or configurational analyses are foundational to scientific advance, as are formal models and experimentation. Combining theory with systematic observation, I would propose that social causality has much to offer and does not require an experiment to bestow credibility, although surely experiments and observational knowledge together are better than either alone. Perhaps because of this symposium, we will not have to read in another 25 years about the sociological road not taken in the study of context.

\section{REFERENCES}

Booth, Charles. 1889. Life and Labor of the People of London. London: MacMillan.

Boruch, Robert, and Ellen Foley. 2000. "The Honestly Experimental Society: Sites and Other Entities as the Units of Allocation and Analysis in Randomized Trials." Pp. 193-238 in Validity and Social Experimentation: Donald T. Campbell's Legacy, edited by Leonard Bickman. Thousand Oaks, Calif.: Sage.

Brannigan, Augustine. 2004. The Rise and Fall of Social Psychology: The Use and Misuse of the Experimental Method. New York: Aldine Transaction.

Bruch, Elizabeth E., and Robert D. Mare. 2006. "Neighborhood Choice and Neighborhood Change." American Journal of Sociology 112:667-709.

Clampet-Lundquist, Susan, and Douglas S. Massey. 2008. "Neighborhood Effects on Economic Self-Sufficiency: A Reconsideration of the Moving to Opportunity Experiment." American Journal of Sociology 114 (1).

Clark, William A. V. 2005. "Intervening in the Residential Mobility Process: Neighborhood Outcomes for Low-Income Populations." Proceedings of the National Academy of Sciences 102:15307-12.

Coleman, James. 1990. Foundations of Social Theory. Cambridge, Mass.: Harvard University Press.

Duncan, Greg J., and Stephen Raudenbush. 2001. "Neighborhoods and Adolescent Development: How Can We Determine the Links?" Pp. 105-36 in Does It Take a 


\section{MTO Symposium: Moving to Inequality}

Village? Community Effects on Children, Adolescents, and Families, edited by Alan Booth and Nan Crouter. State College: Pennsylvania State University Press.

Faris, Robert E., and Warren H. Dunham. 1939. Mental Disorders in Urban Areas: An Ecological Study of Schizophrenia and Other Psychoses. Chicago: University of Chicago Press.

Goering, John, and Judith Feins, eds. 2003. Choosing a Better Life? Evaluating the Moving to Opportunity Social Experiment. Washington, D.C.: Urban Institute Press.

Hagan, John, Ross MacMillan, and Blair Wheaton. 1996. "New Kid in Town: Social Capital and the Life Course Effects of Family Migration on Children." American Sociological Review 61:368-85.

Haynie, Dana, and Scott J. South. 2005. "Residential Mobility and Adolescent Violence." Social Forces 84:361-74.

Heckman, James J. 2005. "The Scientific Model of Causality.” Sociological Methodology 35:1-97.

Heckman, James J., and Jeffrey A. Smith. 1995. "Assessing the Case for Social Experiments." Journal of Economic Perspectives 9:85-110.

Hipp, John R. 2007. "Block, Tract, and Levels of Aggregation: Neighborhood Structure and Crime and Disorder as a Case in Point." American Sociological Review 72: 659-80.

Holland, Paul. 1986. "Statistics and Causal Inference." Journal of the American Statistical Association 81:945-70.

Hong, Guanglei, and Stephen W. Raudenbush. In press. "Causal Inference for TimeVarying Instructional Treatments." Journal of Educational and Behavioral Statistics 33 (2008).

Jencks, Christopher, and Susan E. Mayer. 1990. "The Social Consequences of Growing up in a Poor Neighborhood." Pp. 111-86 in Inner-City Poverty in the United States, edited by Lawrence Lynn and Michael McGreary. Washington, D.C.: National Academies Press.

Katz, Lawrence F., Jeffrey Kling, and Jeffrey B. Liebman. 2001. "Moving to Opportunity in Boston: Early Results of a Randomized Mobility Experiment." Quarterly Journal of Economics 116:607-54.

Kling, Jeffrey, Jeffrey Liebman, and Lawrence Katz. 2007. "Experimental Analysis of Neighborhood Effects." Econometrica 75:83-119.

Land, Kenneth, Patricia McCall, and Lawrence E. Cohen. 1990. "Structural Covariates of Homicide Rates: Are There Any Invariances across Time and Space?" American Journal of Sociology 95:922-63.

Langer, Bruce, and Stanley Michael. 1963. Life Stress and Mental Health. London: Free Press.

Leventhal, Tama, and Jeanne Brooks-Gunn. 2000. "The Neighborhoods They Live In: The Effects of Neighborhood Residence on Child and Adolescent Outcomes." Psychological Bulletin 126:309-37.

Lieberson, Stanley. 1985. Making It Count: The Improvement of Social Research and Theory. Berkeley and Los Angeles: University of California Press.

Lieberson, Stanley, and Freda Lynn. 2002. "Barking up the Wrong Branch: Scientific Alternatives to the Current Model of Sociological Science." Annual Review of Sociology 28:1-19.

Ludwig, Jens, Paul Hirschfield, and Greg J. Duncan. 2001. "Urban Poverty and Juvenile Crime: Evidence from a Randomized Housing-Mobility Experiment." Quarterly Journal of Economics 116:665-79.

Ludwig, Jens, Jeffrey B. Liebman, Jeffrey R. Kling, Greg J. Duncan, Lawrence F. Katz, Ronald C. Kessler, and Lisa Sanbonmatsu. 2008. "What Can We Learn about Neighborhood Effects from the Moving to Opportunity Experiment?" American Journal of Sociology 114 (1). 


\section{American Journal of Sociology}

Massey, Douglas S., and Nancy Denton. 1993. American Apartheid: Segregation and the Making of the Underclass. Cambridge, Mass.: Harvard University Press.

Mayer, Susan E., and Christopher Jencks. 1989. "Growing up in Poor Neighborhoods: How Much Does It Matter?" Science 243:1441-45.

Mayhew, Henry. 1862. London Labor and the London Poor. London: Griffin, Bohn.

Morgan, Stephen, and Christopher Winship. 2007. Counterfactuals and Causal Inference: Methods and Principles for Social Research. New York: Cambridge University Press.

NBER (National Bureau of Economic Research). 2006. "Improved Neighborhoods Don't Raise Academic Achievement." http://www.nber.org/digest/sep06/ w11909.html.

Oakes, J. Michael. 2004. "The (Mis)Estimation of Neighborhood Effects: Causal Inference in a Practicable Social Epidemiology." Social Science and Medicine 58: 1929-52.

Orr, Larry, Judith D. Feins, Robin Jacob, Erik Beecroft, Lisa Sanbonmatsu, Lawrence F. Katz, Jeffrey B. Liebman, and Jeffrey R. Kling. 2003. "Moving to Opportunity Interim Impacts Evaluation." Washington, D.C.: U.S. Department of Housing and Urban Development.

Park, Robert, and Ernest Burgess. 1925. The City: Suggestions for Investigation of Human Behavior in the Urban Environment. Chicago: University of Chicago Press.

Pattillo, Mary E. 1999. Black Picket Fences: Privilege and Peril among the Black Middle Class. Chicago: University of Chicago Press.

Prentice, Deborah, and Dale Miller. 1992. "When Small Effects Are Impressive." Psychological Bulletin 112:160-64.

Raudenbush, Stephen W., and Robert J. Sampson. 1999. “'Ecometrics': Toward a Science of Assessing Ecological Settings, with Application to the Systematic Social Observation of Neighborhoods." Sociological Methodology 29:1-41.

Robins, James. 1999. "Association, Causation, and Marginal Structural Models." Synthese 121:151-79.

Robins, James M., Miguel Ángel Hernán, and Babette Brumback. 2000. "Marginal Structural Models and Causal Inference in Epidemiology." Epidemiology 11:550-60.

Rossi, Peter H., Richard A. Berk, and Kenneth J. Lenihan. 1980. Money, Work, and Crime: Experimental Evidence. New York: Academic Press.

Sampson, Robert J., and Jeffrey D. Morenoff. 1997. "Ecological Perspectives on the Neighborhood Context of Urban Poverty: Past and Present." Pp. 1-22 in Neighborhood Poverty, edited by Jeanne Brooks-Gunn, Greg J. Duncan, and J. Lawrence Aber. New York: Russell Sage.

- 2006. "Durable Inequality: Spatial Dynamics, Social Processes and the Persistence of Poverty in Chicago Neighborhoods." Pp. 176-203 in Poverty Traps, edited by Samuel Bowles, Steve Durlauf, and Karla Hoff. Princeton, N.J.: Princeton University Press

Sampson, Robert J., Jeffrey D. Morenoff, and Felton Earls. 1999. "Beyond Social Capital: Spatial Dynamics of Collective Efficacy for Children." American Sociological Review 64:633-60.

Sampson, Robert J., Jeffrey D. Morenoff, and Thomas Gannon-Rowley. 2002. "Assessing 'Neighborhood Effects': Social Processes and New Directions in Research." Annual Review of Sociology 28:443-78.

Sampson, Robert J., and Patrick Sharkey. 2008. "Neighborhood Selection and the Social Reproduction of Concentrated Racial Inequality." Demography 45:1-29.

Sampson, Robert J., Patrick Sharkey, and Stephen Raudenbush. 2008. "Durable Effects of Concentrated Disadvantage on Verbal Ability among African-American Children." Proceedings of the National Academy of Sciences 105:845-52.

Sanbonmatsu, Lisa, Jeffrey R. Kling, Greg J. Duncan, and Jeanne Brooks-Gunn. 2006. 


\section{MTO Symposium: Moving to Inequality}

"Neighborhoods and Academic Achievement: Results from the Moving to Opportunity Experiment." Journal of Human Resources 41:649-91.

Schlossman, Steven, and Michael Sedlak. 1983. "Chicago Area Project." Crime and Delinquency 29:398-462.

Sharkey, Patrick. 2008. "The Intergenerational Transmission of Context." American Journal of Sociology 113:931-69.

Shaw, Clifford R., and Henry D. McKay. 1942. Juvenile Delinquency and Urban Areas. Chicago: University of Chicago Press.

Shonkoff, Jack P., and Deborah A. Phillips, eds. 2000. From Neurons to Neighborhoods: The Science of Early Childhood Development. Washington, D.C.: National Academies Press.

Sikkema, Kathleen, et al. 2000. "Outcomes of a Randomized Community-Level HIV Prevention Intervention for Women Living in 18 Low-Income Housing Developments." American Journal of Public Health 90:57-63.

Sobel, Michael. 2006. "What Do Randomized Studies of Housing Mobility Demonstrate? Causal Inference in the Face of Interference." Journal of the American Statistical Association 101:1398-1407.

Suttles, Gerald D. 1990. The Man-Made City: The Land-Use Confidence Game in Chicago. Chicago: University of Chicago Press.

Verbitsky, Natalya, and Stephen W. Raudenbush. 2006. "Causal Inference in Spatial Settings: A Case Study of Community Policing in Chicago." Paper presented at the Causal Inference in Neighborhood-Based Research conference, Chicago, December 1.

Wheaton, Blair, and Philippa Clarke. 2003. "Space Meets Time: Integrating Temporal and Contextual Influences on Mental Health in Early Adulthood." American Sociological Review 68:680-706.

Wikström, Per-Olof, and Robert J. Sampson. 2003. "Social Mechanisms of Community Influences on Crime and Pathways in Criminality." Pp. 118-48 in Causes of Conduct Disorder and Serious Juvenile Delinquency, edited by Ben Lahey, Terrie Moffitt, and Avshalom Caspi. New York: Guilford Press.

Wilson, William Julius. 1987. The Truly Disadvantaged: The Inner City, the Underclass, and Public Policy. Chicago: University of Chicago Press.

Zeisel, Hans. 1982a. "Disagreement over the Evaluation of a Controlled Experiment." American Journal of Sociology 88:378-89.

. 1982b. "Hans Zeisel Concludes the Debate." American Journal of Sociology 88:394-96.

Zorbaugh, Henry. 1929. The Gold Coast and the Slum: A Sociological Study of Chicago's Near North Side. Chicago: University of Chicago Press. 